\title{
LA COVA DEL CANTAL (BIAR, ALICANTE)
}

\author{
EDUARDO J. LÓPEZ SEGUÍ, \\ MARCO AURELIO GARCÍA BEBIA, \\ JOSÉ RAMÓN ORTEGA PÉREZ
}

Universidad de Alicante

\begin{abstract}
La Cova del Cantal (Biar, Alicante) es, fundamentalmente, una cueva de enterramiento múltiple de un momento posiblemente avanzado del Calcolítico Pleno. Fue utilizada también en el Horizonte Campaniforme de Transición y en la Edad del Bronce, encontrando restos de ocupaciones posteriores. Parte de los materiales estudiados pertenece a dos colecciones privadas, siendo el resto de la excavación de urgencia por nosotros realizada. El ajuar está compuesto principalmente por formas cerámicas, puntas de flecha de sílex, hachas y azuelas pulimentadas y por un anillo, un puñal de lengüeta y cuatro punzones de metal. En ella se inhumaron al menos nueve individuos que corresponden en su mayoría al momento Calcolítico.

The "Cova del Cantal" is a multiple burial cave from the late Calcolithic, although it was also visited during the Bell-Beaker Period, the Bronze Age and later. The studied materials belong to two private collections and to a rescue excavation made by the authors. They are principally varied pottery, silex arrowheads, pulimented axes and adzes, a ring, a tongue-dagger and four metallic punches. At least nine individuals were buried, most of them in the $\mathrm{Cal}$ colithic Period.
\end{abstract}

\section{INTRODUCCIÓN}

Cuando se recogían los datos necesarios para la elaboración de la Memoria de Licenciatura de uno de los autores (E. López Segui), tuvimos la oportunidad de estudiar dos colecciones privadas en las que se encontraba un significativo conjunto de materiales arqueológicos recogidos en la Cova del Cantal.

Esta cueva, cuyo nombre fue dado por su proximidad al paraje conocido como el Cantal de Ferriz, se encuentra situada en el término municipal de Biar (Alicante) (Fig. 1). De ella se extrajo una considerable cantidad de materiales arqueológicos de diferente adscripción cultural en sucesivas remociones de tierra, realizadas desde octubre de 1986 a abril de 1988.

En nuestra primera visita pudimos observar que la cueva se dividía en dos salas separadas por un estrangulamiento de las paredes (la tercera fue descubierta con posterioridad). En la primera de ellas, acceso principal a la cavidad, comprobamos que las remociones de tierra la habían destruido prácticamente en su totalidad, mientras que la otra parecía que sólo había sido afectada en la zona central. 


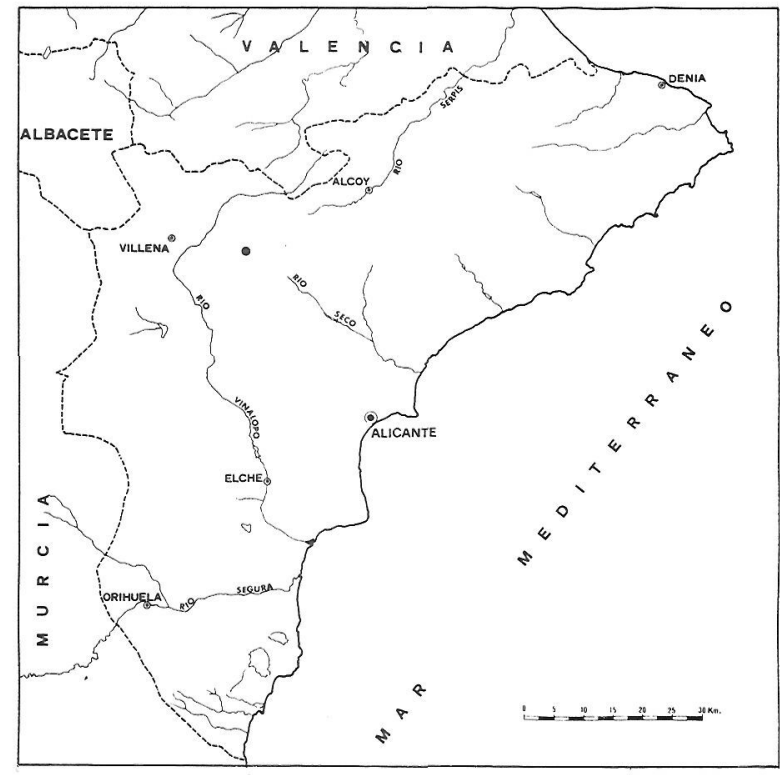

Fig. 1.- Situación de la cueva.

Los propietarios de las colecciones privadas P. Amorós y F. Hernández, pusieron a nuestra disposición información escrita que permite reconstruir en parte la distribución espacial de los materiales extraidos, si bien, dada su procedencia, sólo puede tener un valor indicativo. Con todo, un estudio pormenorizado de la distribución de los ajuares y restos humanos evidenciaba el mayor interés arqueológico de la segunda sala por estar sólo removida en parte, por la mayor concentración de materiales prehistóricos y por la exclusividad de los restos humanos si exceptuamos los dientes.

El inminente peligro de destrucción que corría el yacimiento, la calidad de los materiales extraidos

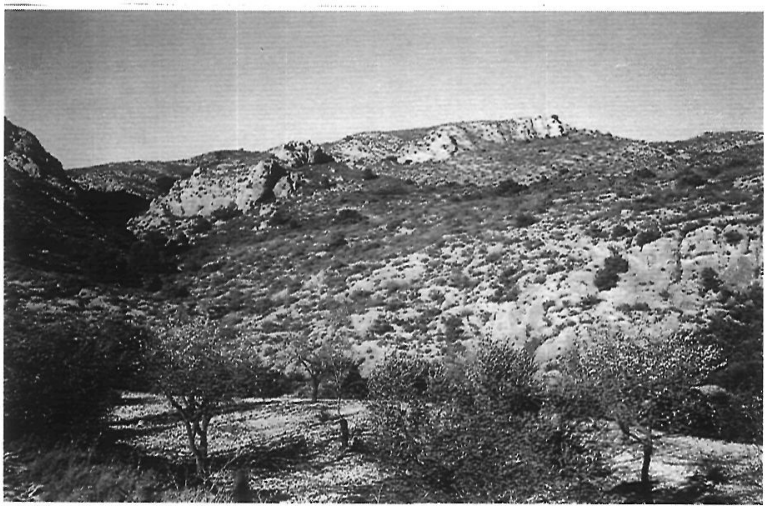

Lám. 1.1.- Situación.

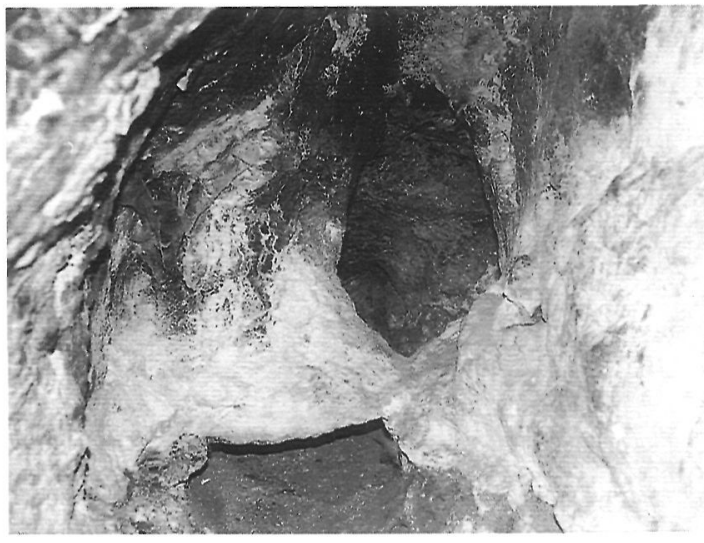

Lám. 1.2.- Zona de paso entre las salas 1 y 2.

por los coleccionistas, la posibilidad de reconstruir parcialmente su distribución, la existencia de zonas intactas en la cueva, su situación en el paso natural que comunica el Alto Vinalopó y l'Alcoià (zonas relativamente conocidas y con gran cantidad de yacimientos coetáneos al que estamos tratando), el hecho de que pudiese contribuir a explicar el fenómeno de la aparición de la Edad de los Metales en el

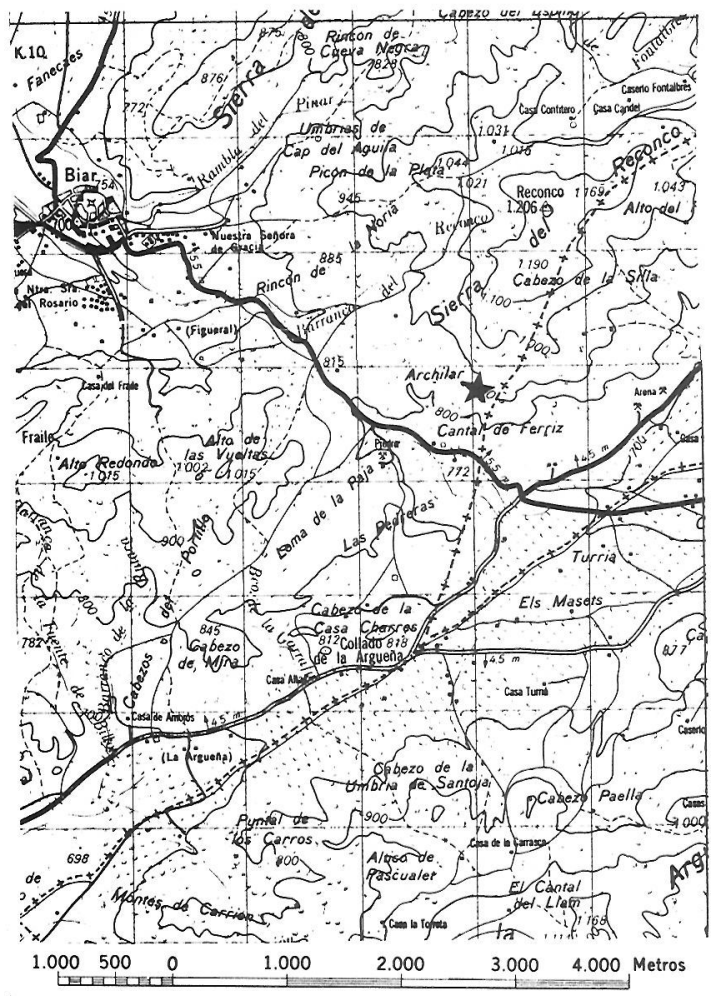

Fig. 2.- Ubicación geográfica. 


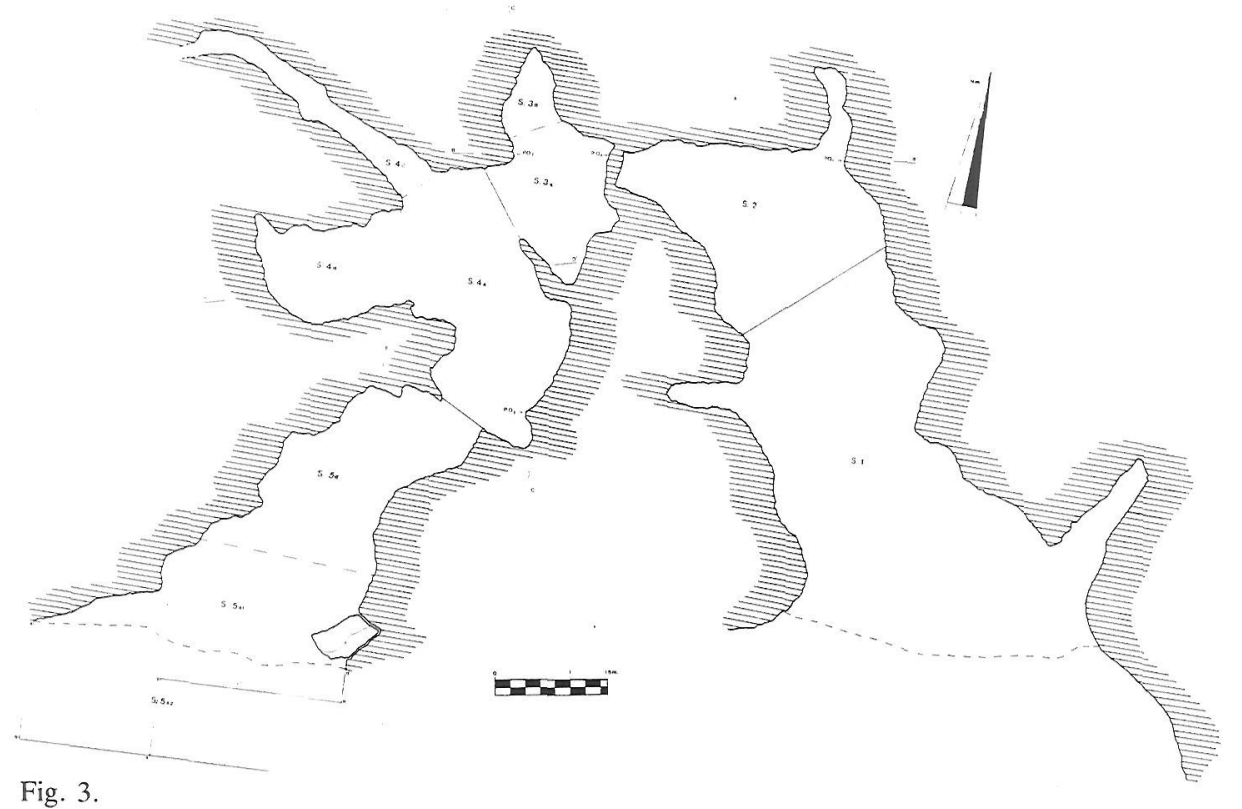

Fig. 3.

País Valenciano y la escasez de excavaciones modernas de este tipo de yacimientos, nos llevó a solicitar un permiso de excavación de salvamento. Concedido éste a nombre de Mauro S. Hernández, quien delegó en nosotros el trabajo, planteamos la excavación con el objetivo de rescatar el mayor volumen de información posible y evitar la destrucción de un yacimiento que, tras un primer análisis, se revelaba muy interesante.

\section{SITUACIÓN}

La Cova del Cantal se encuentra situada en la Sierra del Reconco, que forma parte del conjunto de alineaciones que delimitan por el norte la Foia de Castalla (Fig. 2). La citada sierra se articula como una prolongación hacia el suroeste de la Sierra de Onil. Ambas participan en líneas generales de una misma unidad, ofreciendo una pendiente uniforme hacia la Foia de Castalla. Sus pliegues tienen una dirección suroeste-noreste, formando parte del dominio del Prebético interno (LÓPEZ GÓMEZ y ROSSELLÓ VERGER, 1978).

La Sierra del Reconco pertenece a los términos municipales de Biar y Onil. Es una formación ancha con una altura máxima de $1.206 \mathrm{~m}$. sobre el nivel del mar que decrece escalonadamente hacia el sur. La Cova del Cantal se sitúa en el extremo suroeste de aquélla, en la zona de intersección entre el alto cortado vertical que desciende desde la cima y la ladera que va a desembocar al Cantal de Ferriz, en término municipal de Biar (Lám. 1.1). Su altura sobre el nivel del mar es de $880 \mathrm{~m}$., y de 140 $\mathrm{m}$. sobre el nivel del valle; la pendiente es del $42 \%$.

Desde su boca se puede divisar una pequeña extensión del sector noroeste de la Foia de Castalla, así como parte del valle que conduce a Sax y la entrada al Puerto de Biar, sobre la que se sitúa. De igual forma, la mayor de sus bocas es visible desde la práctica totalidad del espacio visual que ella misma controla.

Coordenadas geográficas: $36^{\circ} 35^{\prime} 13^{\prime \prime}$ latitud norte, $0^{\circ} 46^{\prime}$ 67' 'longitud oeste del Meridiano de Greenwich (según la hoja de Castalla número 2833 (846) del Mapa del Servicio Geográfico del Ejército, escala 1:50.000, en la edición de 1959 .

\section{DESCRIPCIÓN}

La cueva se abre en las formaciones calizas que dan lugar a la sierra. La planta, irregular, presenta una forma que esquemáticamente se asemeja a una «U» abierta, pudiendo distinguir en ella tres salas con dos bocas orientadas al suroeste (Fig. 3).

La situada más al este tiene una anchura de $3,40 \mathrm{~m}$. y $2,45 \mathrm{~m}$. de altura en la cornisa; a través de ella se accede a la primera sala (Sala 1). La superficie de ésta es de 16,52 metros cuadrados, de- 


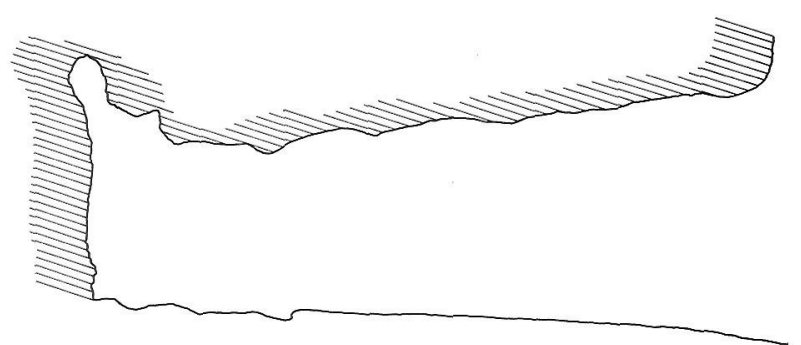

SECCIÓN A - A'

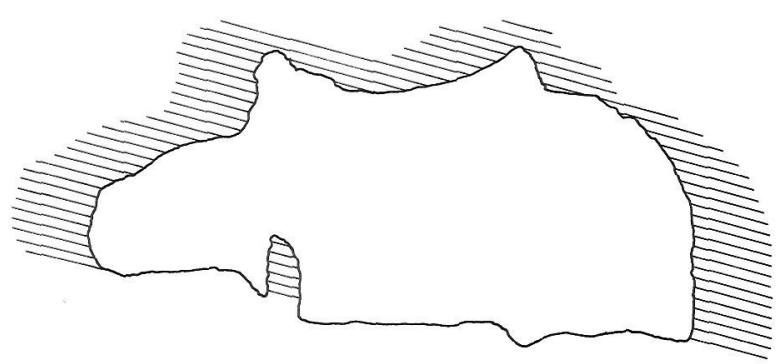

SECCIÓN B - B'

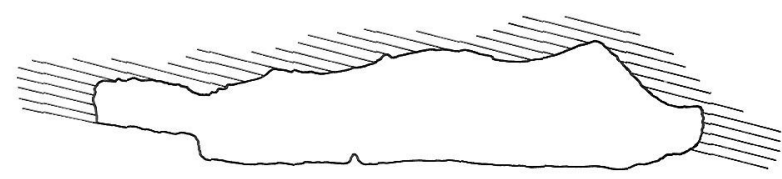

SECCIÓN C - C'

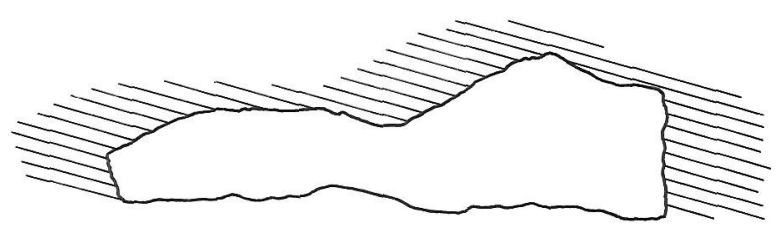

SECCIÓN D - D'

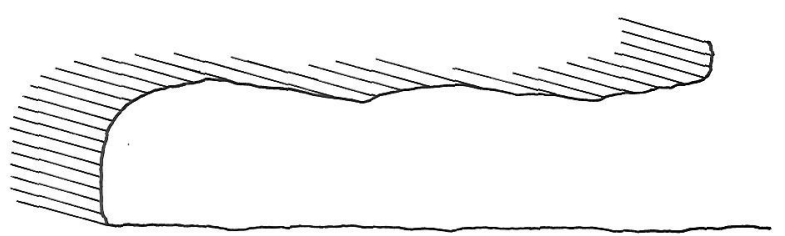

SECCIÓN E - E' creciendo la altura 1,05 metros desde la boca hasta el final de la sala (de 2,45 a 1,40 metros). Es la más iluminada y espaciosa de las tres; tiene un grado de humedad medio atestiguado por la presencia en el techo de goteras continuas.

En la Sala 1 podemos observar la existencia de una prolongación de forma triangular situada en el sector noroeste que se estrecha conforme avanza hacia la citada dirección. En el extremo de ésta se abre una especie de galería elevada, alargada y estrecha $(0,74 \times 0,45$ metros $)$ por la que se produce el contacto entre la Sala 1 y la 2 (Lám. 1.2). Ésta era la única vía de acceso a la Sala 2 hasta que se realizó la excavación, que puso al descubierto la tercera sala y la segunda boca de la cavidad.

Antes de iniciar la excavación, que amplió la extensión de la sala por la inclinación,de sus paredes y el levantamiento de piedras caidas del techo, la superficie era de 5,33 metros cuadrados y la altura media en el centro de 0,70 metros, decreciendo hacia los lados con la consiguiente dificultad para desenvolverse en ella. Observamos la existencia de una prolongación triangular en la zona suroeste (4 B) con una superficie de 6,3 metros cuadrados, así como la de una gatera de $0,45 \mathrm{~m}$. de anchura media y una profundidad mínima de 5,3 m. El grado de humedad es bastante alto, observando la presencia de goteras que, en alguna ocasión, han producido formaciones estalagmíticas. La iluminación natural es muy escasa, siendo necesaria la utilización de luz artificial antes de la excavación de la Sala 3.

En el extremo sur de la Sala 2, el nivel inalterado de relleno y la presencia de una gran piedra desprendida del techo imposibilitaba el acceso a la Sala 3, cerrado de igual forma en el exterior por la continua deposición de piedras desprendidas de la cornisa, la presencia de una gran carrasca y abundante vegetación, y la existencia de grandes bloques de piedra caídos del techo con posterioridad a la utilización de la cueva en época prehistórica. Una vez excavada, pudimos comprobar cómo el acceso exterior se produce a través de un espacio alargado y poco profundo, ya en el interior de la cornisa, que sirve de antesala a otro de forma más o menos rectangular con una superficie de 10,4 metros cuadrados y una altura media de $1,2 \mathrm{~m}$. La boca está $2,1 \mathrm{~m}$. por encima del nivel de base de la situada más al este (Lám. 2.6), siendo el grado de iluminación considerablemente inferior. El grado de humedad relativa observado es el más bajo de las tres salas. 
El yacimiento ha sufrido constantes remociones en los últimos tres años; el resultado de éstas ha sido la destrucción prácticamente total de los niveles arqueológicos de la Sala 1 , cuyo suelo actual está formado por la tierra removida y las terreras de los clandestinos. En algunos sectores de las paredes de la misma han quedado las huellas del nivel de tierra extraído, que llega a tener una potencia de $25 \mathrm{~cm}$.

La Sala 2 fue removida parcialmente. El mayor grado de extracción de tierras se localizaba en la zona central, con una mayor incidencia en el sector más próximo a la entrada desde la Sala 1. Se mantenían intactas las partes más cercanas a la pared y la zona más meridional, lugar en el que las remociones no llegaron a destruir totalmente los niveles arqueológicos. De la misma manera, se preservaron la prolongación situada al suroeste y la gatera antes nombradas. En superficie se podía observar la existencia de una gran cantidad de tierra removida no extraida de la cavidad.

La Sala 3 permaneció intacta porque el acceso a la misma entrañaba grandes dificultades.

\section{EXCAVACIÓN}

Como paso previo a la explicación del proceso de excavación de la Cova del Cantal, procederemos a exponer la secuencia de las zonas no alteradas, lo que simplificará considerablemente la exposición.

La estratigrafía es relativamente simple, prácticamente la misma en toda la superficie excavada. La Capa I está formada por una tierra gris muy suelta, polvorienta en ocasiones, con gran cantidad de restos de pequeños animales, roedores y piedras sueltas de pequeño tamaño. El espesor medio general es de $10 \mathrm{~cm}$. Únicamente en una zona se alteraba esta uniformidad al preceder a la tierra gris una capa de concreciones de carbonato cálcico que originó una pequeña formación estalagmítica.

La Capa II, tierra de color marrón, granulosa y poco compacta, con multitud de pellas blancas, es la única fértil arqueológicamente. En ella se encuentran materiales arqueológicos desde el inicio hasta la zona de contacto con la Capa III. Presenta multitud de piedras desprendidas del techo de tamaño pequeño y mediano. Su potencia media es de 25-30 cm.

Una tierra roja, arcillosa, compacta y con un origen posiblemente relacionado con la acción del agua, da lugar a la Capa III. Sobre ella, los materiales arqueológicos situados a mayor profundidad y piedras de mediano y gran tamaño caídas del techo. Estéril desde el punto de vista arqueológico, configura el suelo original de la cueva, a la vez que supone el tránsito entre la capa fértil y la roca en descomposición. Tiene un espesor medio de $5-8 \mathrm{~cm}$. La Capa $I V$ corresponde a la roca en descomposición, mientras que la Capa $V$ es ya la roca madre.

Como hemos dicho antes, ésta es la estratigrafía encontrada en zonas no removidas. En gran parte de la superficie excavada, la Capa $I$ y parte de la II habían sido alteradas.

Antes de iniciar la excavación, decidimos dividir la cueva en cuatro sectores, cinco con el descubrimiento de la Sala 3. Comienzan a numerarse desde la boca situada al E, quedando los sectores 1 y 2 en la Sala 1, el 3 y 4 en la Sala 2 y el 5 en la Sala 3. Los tres últimos fueron nuevamente divididos en subsectores que responden a la necesidad de individualizar determinadas zonas en el proceso de excavación.

Comenzamos a excavar el Sector 2, despreciando en principio el 1 (en el que encontramos en superficie seis dientes humanos) por su pésimo estado de conservación. En el citado en primer lugar, los excavadores clandestinos habían levantado gran parte de la capa fértil, sin embargo decidimoṣ excavarlo para recuperar el material que pudiese quedar, a la vez que serviría para conectar ambas salas. En este sector encontramos algunos restos de microfauna y pequeños animales en la capa superficial, así como seis piezas dentarias humanas, dos pequeños fragmentos de cerámica hecha a mano, una punta de flecha foliácea de sílex y el extremo de otra al pie del estrangulamiento que da paso al Sala 3, ya en contacto con la Capa III. Realizamos un sondeo hasta la roca madre comprobando que en la zona en la que la ausencia de piedras permitía profundizar, la Capa III tiene un espesor máximo de $60 \mathrm{~cm}$. y una extensión variable que se reduce a medida que gana terreno la roca.

En el Sector 3 distinguimos una zona central (3A) en la que el nivel dejado por los clandestinos correspondía a la Capa III, sobre la que se encontró una mínima cantidad de microfauna. Alrededor de este área central quedaban espacios no alterados. En el situado al oeste (T. O.), encontramos, sobre un derrumbe de piedras del techo, dos dientes, restos de un cráneo y un cúbito humanos, una punta 


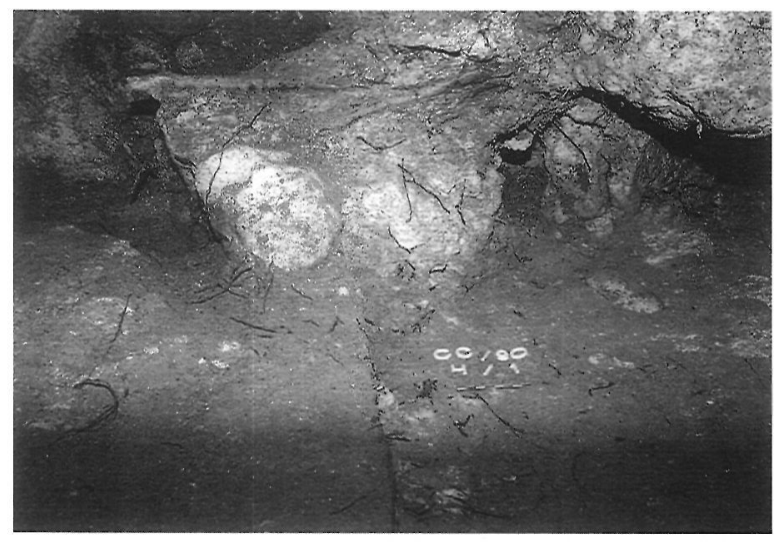

Lám. 1.3.- Sector 4. Restos humanos y hacha pulimentada.

de flecha foliácea de sílex y una pequeña cantidad de huesos de roedores. En el situado al sur (T. S.), hallamos dos fémures humanos, fragmentos de un cráneo también humano y un maxilar inferior de ovicáprido joven muy cerca de éste. Hacia el norte del sector se forma un pequeño entrante (3B) que dejamos en reserva porque estaba muy arrasado.

El Sector 4 presenta una zona central (ensanchada hacia el sur) en la que se abren dos entrantes (A y B). En la tierra revuelta encontramos una punta de flecha foliácea y ocho dientes humanos. En el ensanchamiento, en la Capa II, un cráneo, un fémur y un peroné humanos, una azuelita, una punta de flecha de pedúnculo y aletas, otra foliácea y una romboidal ya en el tránsito a la Capa III. En el ex-

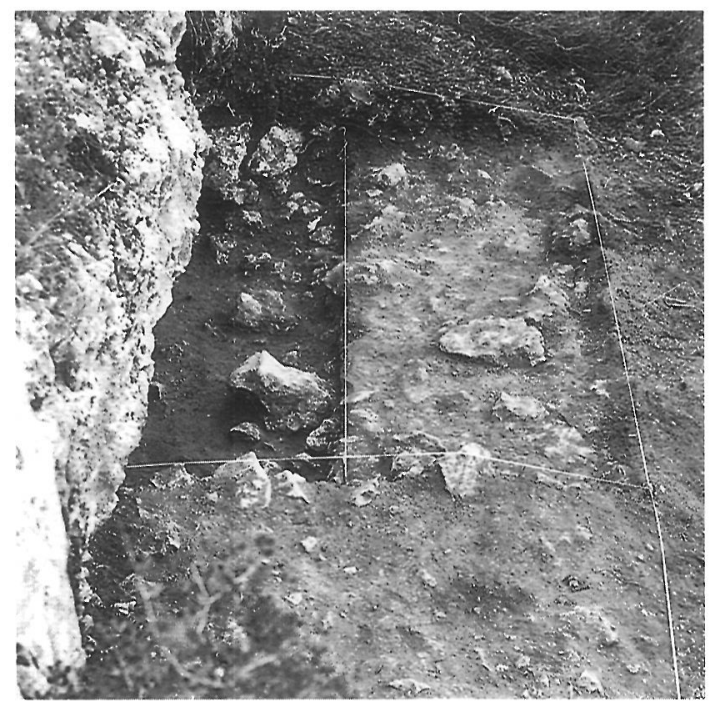

Lám. 1.4.- Sector 5A2. Este sector permite acceder a la Sala 3.

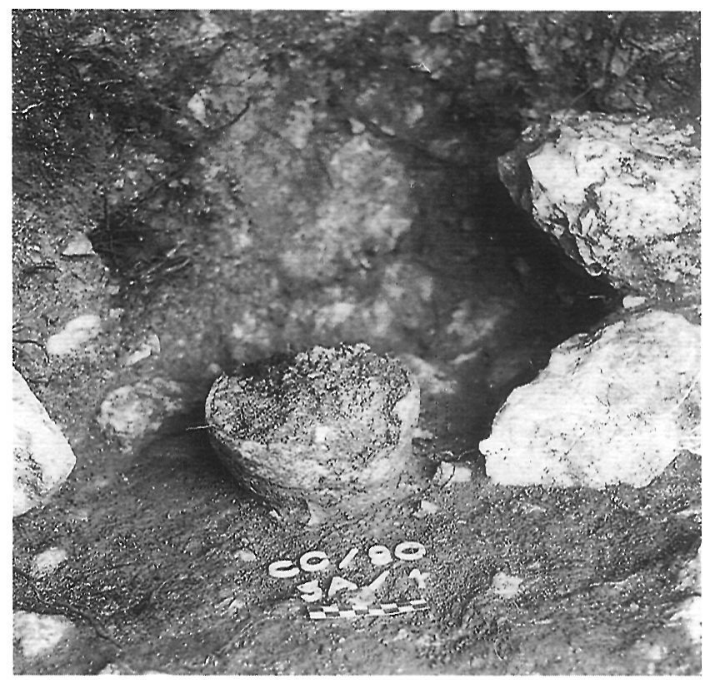

Lám. 1.5.- Vasija (fig. 4.1.) y hacha sobre capa III.

tremo sur del sector, encontramos un cráneo humano entre una gran piedra desprendida del techo y la pared de la cueva y, junto a éste, un maxilar inferior de cabra u oveja joven y una punta de flecha foliácea. A mayor altura, sobre una piedra caída del techo y sepultados parcialmente por otra con una cara plana, se hallaron un fémur, una tibia y restos de una mandíbula inferior humanos (Lám. 1.3). En el subsector A, en la Capa I, dos fragmentos de cerámica prehistórica, una considerable cantidad de microfauna y huesos de roedores y dos puntas de flecha de pedúnculo y aletas. En la boca encontramos una lámina de sílex y un hacha pulimentada.

$\mathrm{El}$ acceso al Sector 5 desde el interior se veía interrumpido por la presencia de una gran piedra desprendida del techo, lo que obligó a comenzar la excavación desde el exterior. La entrada a la cueva por esta segunda boca venía precedida por una gran abertura de la cornisa de 4,5 metros de longitud y escasa profundidad. Para acceder al interior, nos vimos obligados a extraer una gran cantidad de relleno que la taponaba casi por completo (Lám. 1.4). En este sector, intacto por otro lado, distinguimos entre 5A 2 (exterior de la cornisa) 5A 1 (interior de la cornisa y zona de ensanchamiento de la boca) y 5B (interior de la cueva propiamente dicho).

En el sector 5A hallamos tres azuelas, dos hachas, dos puntas de flecha foliáceas y una vasija completa de borde entrante, labio curvo, base plana y cuerpo globular, ésta sobre la Capa III (Lám. 1.5). Destaca la asociación en el extremo es- 


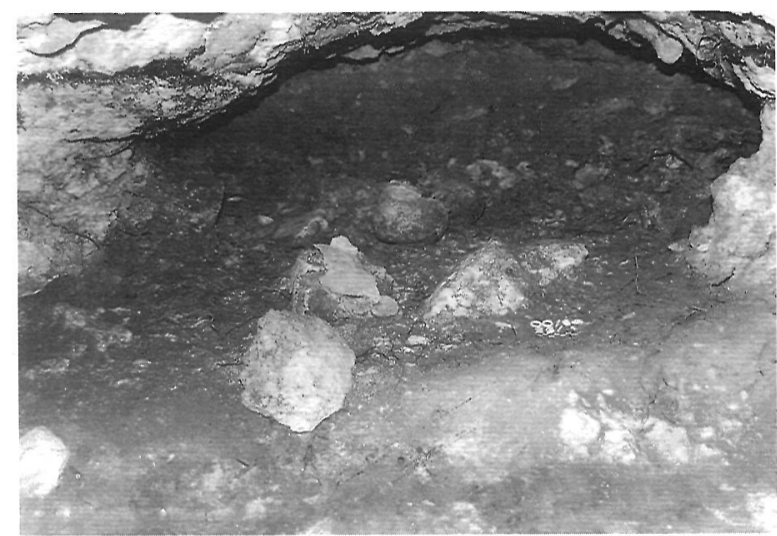

Lám. 1.6.- Sector 5B. Restos humanos y cerámica (figs. 4.2. y 5.1.).

te del sector de una punta de flecha foliácea, la vasija descrita, un hacha y una azuela.

En el Sector 5B, además de restos de fauna de pequeños animales y microfauna en la Capa I, había una gran cantidad de restos humanos que forma un amontonamiento de más de veinte centímetros de espesor, destacando los siete cráneos hallados en él. Asociados, seis vasijas, dos punzones de metal de sección cuadrada, un hacha pulimentada, ocho puntas de flecha foliáceas, tres de pedúnculo $\mathrm{y}$ aletas y una romboidal (Láms. 1.6, 2.1, 2.2, 2.3, 2.4 y 2.5). Todos los materiales se sitúan en la Capa II o en el tránsito a la Capa III. Hay que destacar que tanto los restos humanos como el ajuar es-

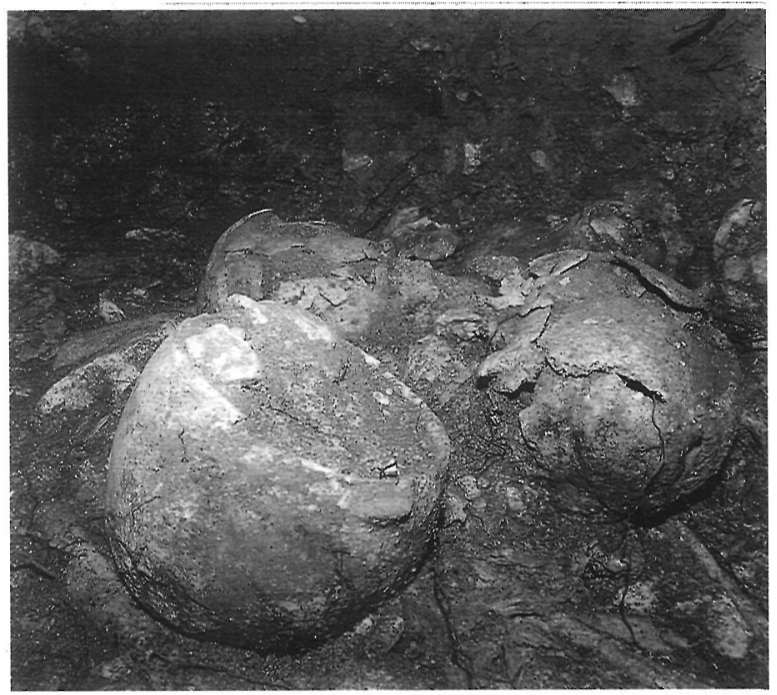

Lám. 2.1.- Sector 5B. Detalle de los materiales de la lámina 1.6.

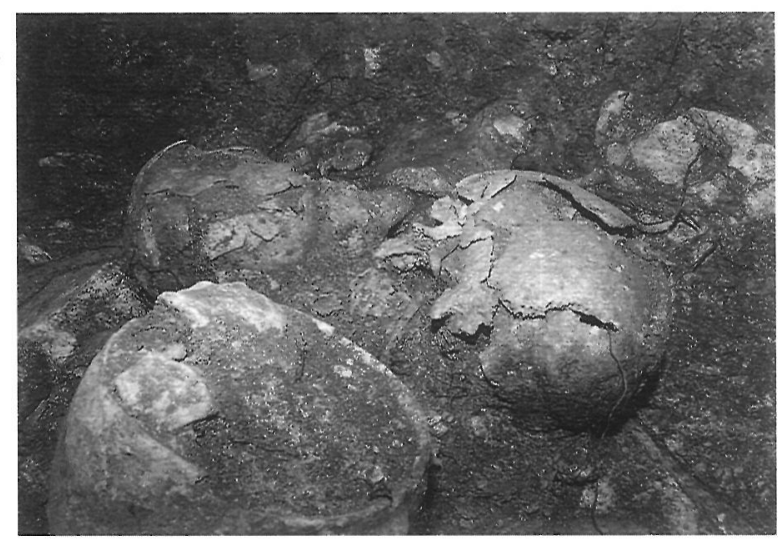

Lám. 2.2.- Sector 5B. Detalle de los materiales de la lámina 1.6 .

taban en los dos tercios situados más al oeste de la cavidad, mientras que el pasillo donde se produce en contacto en el Sector 4 carece de restos materiales.

\section{MATERIALES}

\section{Cerámica}

- Vasija completa de tendencia esférica, borde entrante con labio curvo y base plana. Asa de lengüeta próxima al borde; ignoramos por fractura si tenía otra simétrica. Superficie exterior e interior alisadas. Pasta no cuidada con desgrasante grande. Dimensiones (cm.): altura 10, diámetro de la boca 11,5, diámetro máximo 13,4. Sector 5A. Figura 4.1.

- Vasija de cuerpo globular, borde entrante con extremo plano y base convexa. Dos asas de lengüeta simétricas de sección prácticamente rectangular y grandes dimensiones, situadas inmediatamen-

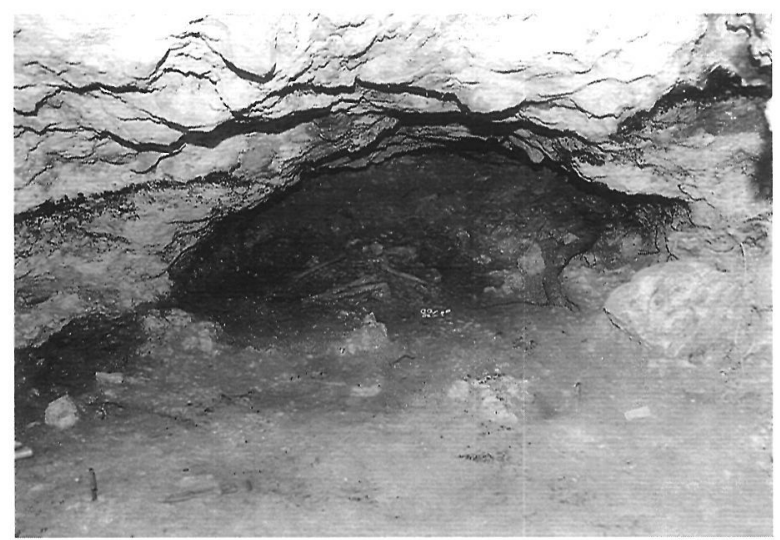

Lám. 2.3.- Sector 5B. Restos humanos bajo los de 1.6. 


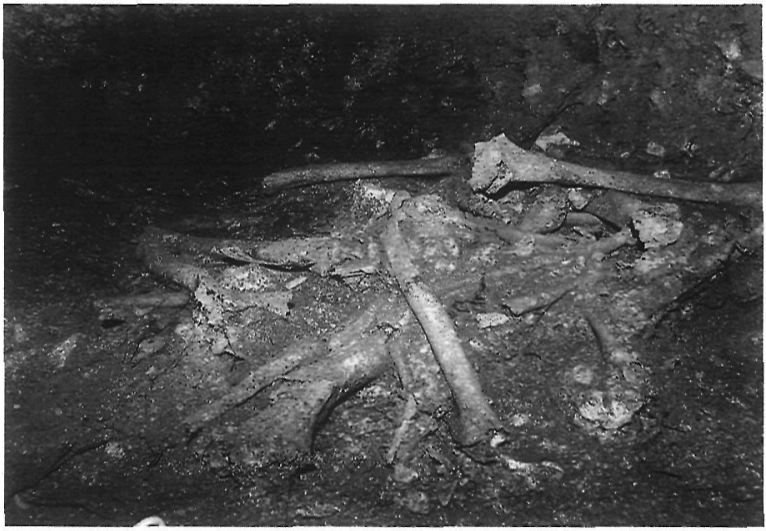

Lám. 2.4.- Sector 5B. Detalle de la lámina 2.3.

te sobre la línea que marcaría el tercio inferior de la vasija; arrancan desde el diámetro mayor. Superficie exterior e interior alisadas. Pasta cuidada con desgrasante pequeño. Dimensiones (cm.): altura 20,7 , diámetro boca 12,3 , diámetro máximo 20,9. Sector 5B. Fig. 4.2.

- Vasija de tendencia esférica, borde entrante con extremo biselado al interior y ligero engrosamiento exterior y base plana. Asa de lengüeta de sección triangular cercana al borde; ignoramos por fractura si tenía otra simétrica. Superficie exterior e interior alisadas. Pasta cuidada con desgrasante pequeño. Dimensiones (cm.): altura 12,3, diámetro boca 12,3, diámetro máximo 15,2. Sector 5B. Fig. 5.1.

- Vasija semiesférica de borde recto ligeramente entrante con extremo apuntado y base convexa. Superficie exterior bruñida e interior alisada. Pasta cuidada con desgrasante pequeño. Dimensiones

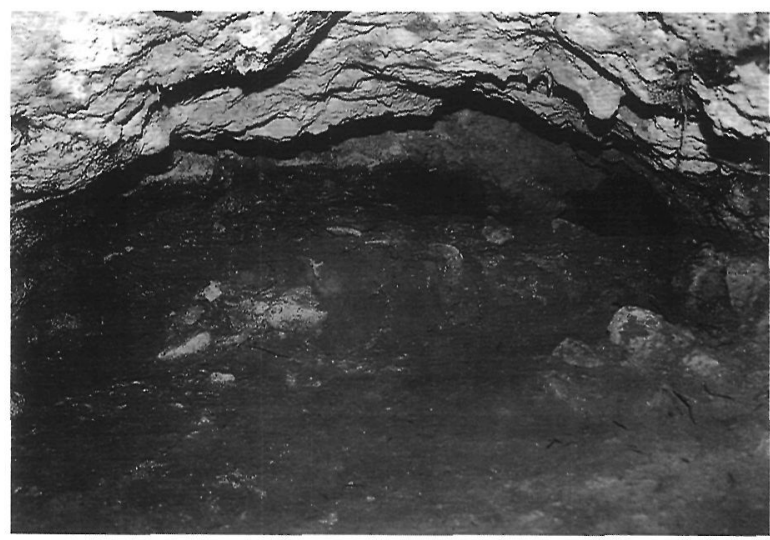

Lám. 2.5.- Sector 5B. Segundo tramo. Restos humanos y azuela pulimentada.
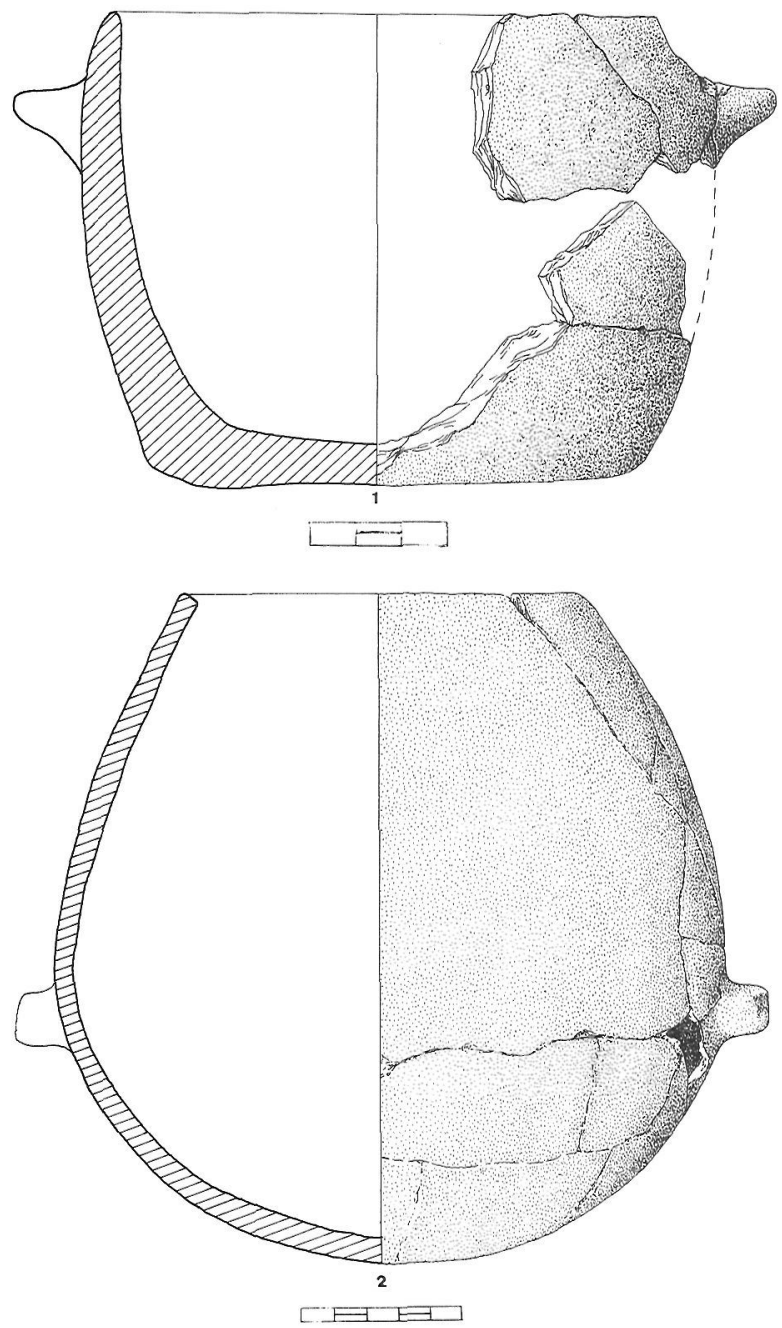

Fig. 4.

(cm.): altura 11, diámetro boca 12,5 , diámetro máximo 13,5. Sector 5B. Fig. 5.2.

- Vasija cilíndrica de borde recto con extremo redondeado y base convexa. Superficie interior y exterior alisadas. Pasta no cuidada con desgrasante mediano y grande. Dimensiones (cm.): altura 10,6, diámetro boca 8,2 , diámetro máximo 8,9 . Sector $5 \mathrm{~B}$. Fig. 7.1.

- Vasija con forma de casquete esférico de borde exvasado con extremo redondeado y base convexa. Pequeña asa de cinta horizontal de sección circular próxima al borde; ignoramos por fractura si tenía otra simétrica. Superficie exterior e interior alisadas. Pasta cuidada con desgrasante pequeño. Dimensiones (cm.): altura 7, diámetro boca 17,5, diámetro máximo 17,5 . Sector 5B. Fig. 6.1. 

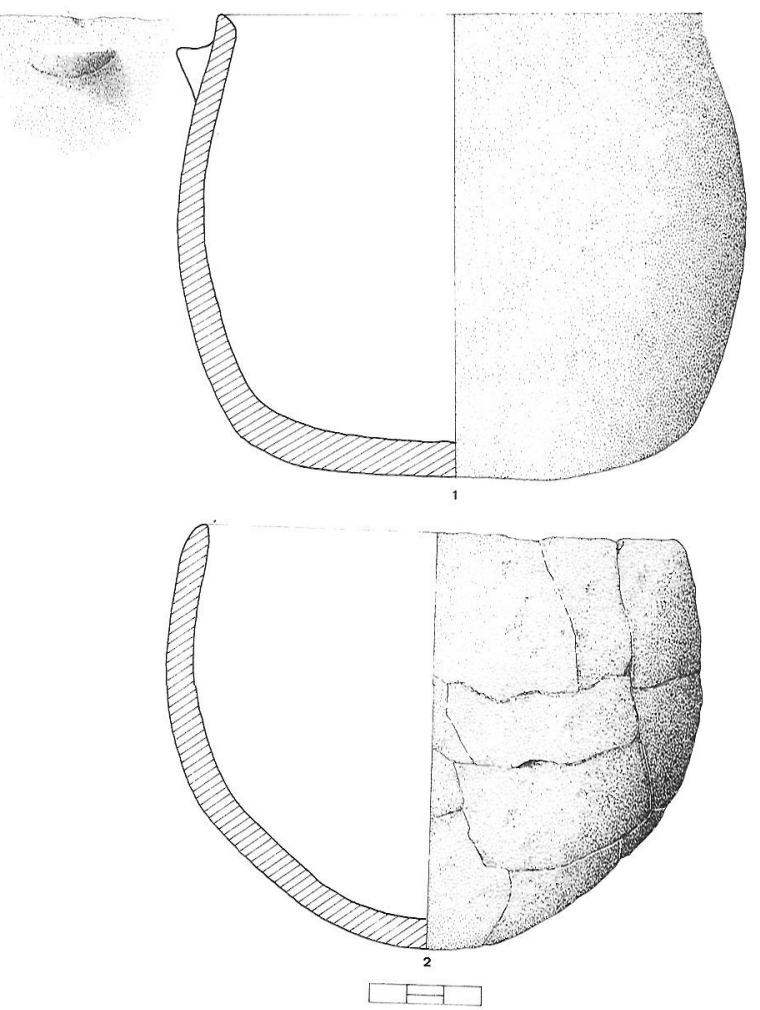

Fig. 5.

- Vasija de tendencia esférica, borde entrante irregular engrosado al exterior y base plana. Superficie exterior e interior alisadas. Pasta cuidada con desgrasante mediano. Dimensiones (cm.): altura 11 , diámetro boca 15,1, diámetro máximo 15,3. Sector 5B. Fig. 7.2.

- Vasija semiesférica con extremo apuntado y base de tendencia plana. Superficie exterior e interior alisadas. Pasta de mediana calidad con desgrasante pequeño y mediano. Dimensiones ( $\mathrm{cm}$.): altura 7,9, diámetro boca 14,6 , diámetro máximo 15,1. Col. P. Amorós. Fig. 8.1.

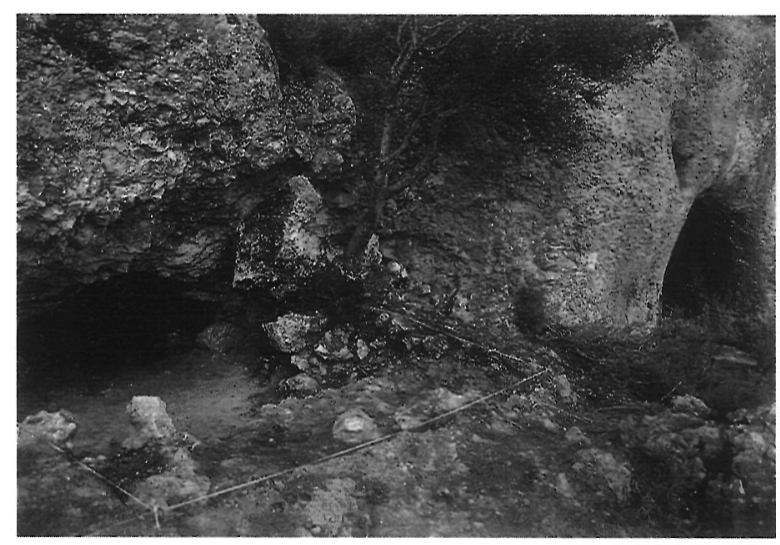

Lám. 2.6.- Bocas de la cueva.

- Vasija semielipsoide horizontal de borde exvasado con extremo redondeado y base plana. Superficie exterior e interior alisadas, erosionada la segunda. Pasta cuidada con desgrasante mediano. Dimensiones (cm.): altura 4,5, diámetro boca 16 , diámetro maximo 16. Col. P. Amorós. Fig. 8.2.

- Vasija elipsoide horizontal de borde entrante con extremo plano engrosado al exterior y base plana. Presenta un asa de lengüeta apuntada de implantación horizontal. Superficie exterior e interior alisadas. Pasta cuidada con desgrasante pequeño y mediano. Dimensiones (cm.): altura 12,6, diámetro boca 16, diámetro máximo 17,1. Col. P. Amorós. Fig. 9.1.

- Pequeño fragmento de borde recto de extremo curvo. Decoración: en la cara externa tres líneas incisas horizontales paralelas al borde, cortan dos de ellas los bordes de fractura, no alcanzando la central uno de ellos. Diámetro aproximado 7,1 cm. Superficie externa e interna alisadas. Pasta cuidada con desgrasante pequeño. Col. P. Amorós. Fig. 9.2.

- Fragmento de pequeña vasija de carena baja. Diámetro $13 \mathrm{~cm}$. Superficie externa e interna bru-

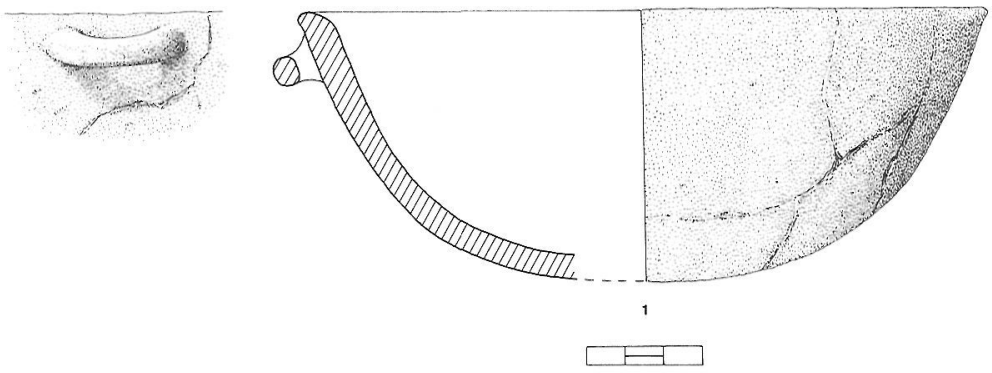

Fig. 6. 

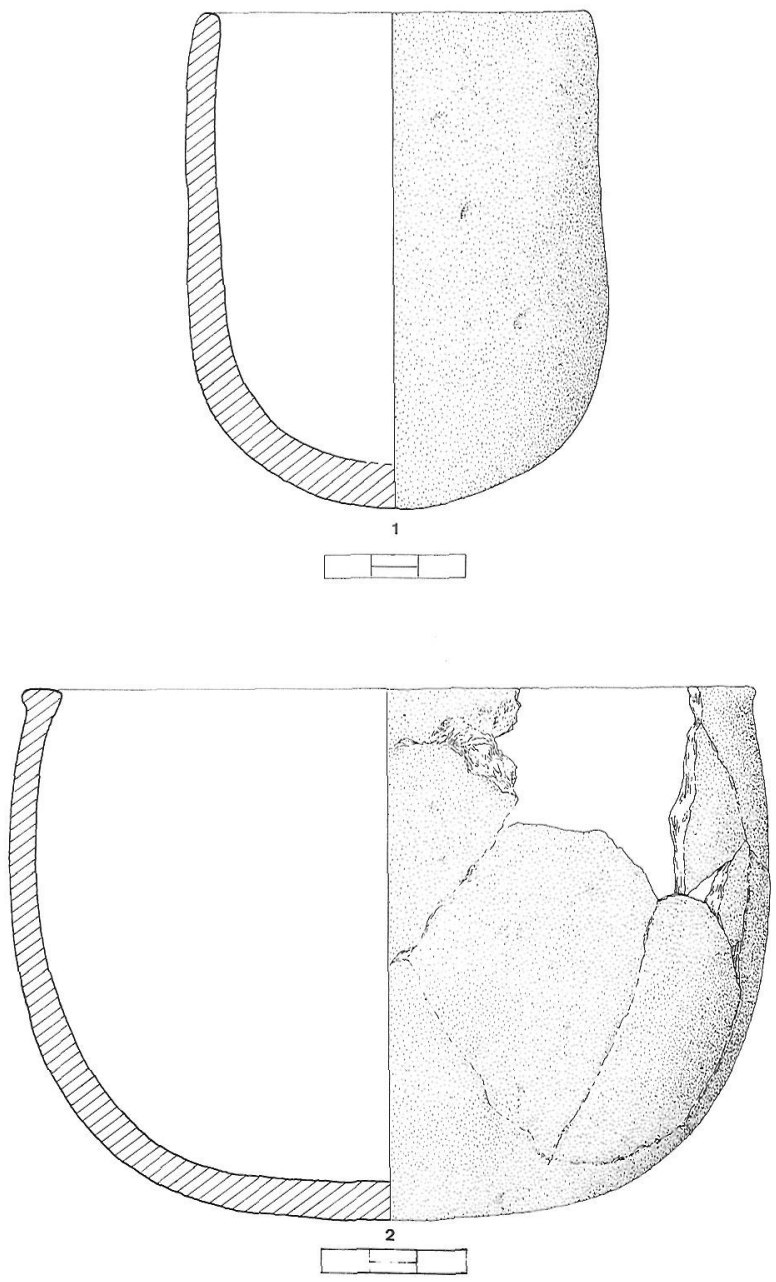

Fig. 7.

ñidas. Pasta cuidada con desgrasante pequeño. Col. P. Amorós. Fig. 9.3.

- Fragmento de pie de copa con base y extremo redondeados. Diámetro $13,6 \mathrm{~cm}$. Superficie externa e interna bruñidas. Pasta cuidada con desgrasante mediano; mica dorada. Col. P. Amorós. Fig. 10.1 .

- Fragmento de vasija de borde exvasado con extremo curvo. Superficie interna y externa alisadas. Pasta cuidada con desgrasante pequeño. Diámetro, $16 \mathrm{~cm}$. Sector 3/4. Fig. 10.2.

- Fragmento de vasija de borde exvasado con extremo curvo. Superficie interior y exterior alisadas. Pasta cuidada con desgrasante pequeño. Sector 1. Superficie. Fig. 11.1.

- Fragmento de borde exvasado con labio marcado y extremo curvo. Superficie interior alisada y
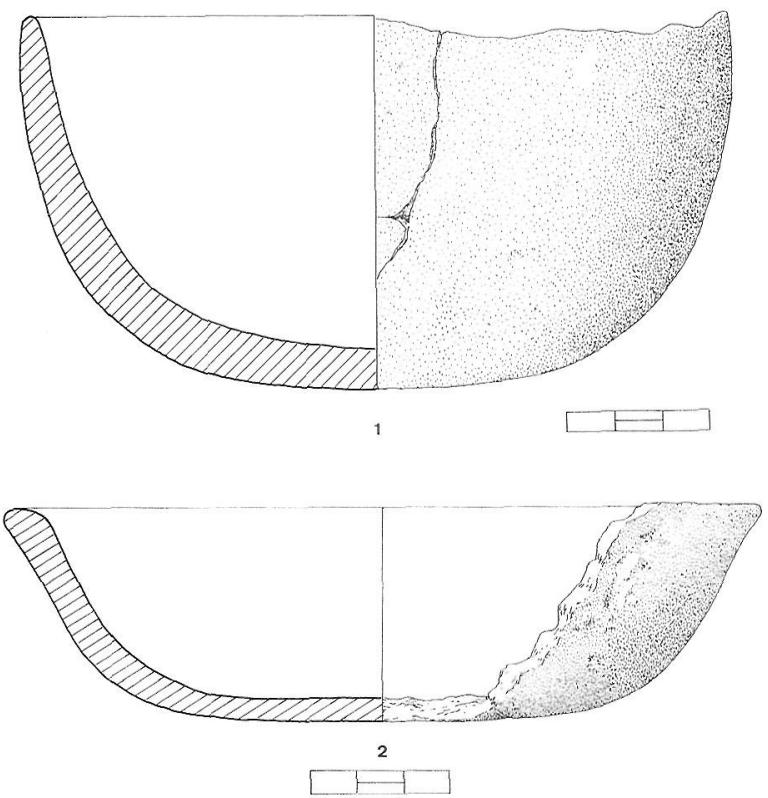

Fig. 8 .

exterior bruñida. Pasta cuidada con desgrasante mediano. Sector 4. Superficie. Fig. 11.2.

- Fragmento de borde exvasado con extremo curvo. Superficie interior y exterior alisadas. Pasta cuidada con desgrasante pequeño. Sector 1. Superficie.

- Fragmento de borde recto con extremo redondeado. Superficie externa e interna aisladas. Pasta cuidada con desgrasante mediano. Diámetro boca $8,8 \mathrm{~cm}$. Col. P. Amorós. Fig. 10.3 .

- Fragmento de borde exvasado con extremo redondeado. Superficie externa e interna bruñidas. Pasta cuidada con desgrasante mediano. Col. P. Amorós.

- Fragmento de borde ligeramente exvasado con extremo redondeado. Superficie externa e interna alisadas. Pasta cuidada con desgrasante pequeño. Col. P. Amorós.

- Fragmento de borde entrante con extremo redondeado. Superficie externa e interna alisadas. Pasta cuidada con desgrasante mediano. Col. P. Amorós.

- Fragmento de cuerpo. Decoración pintada de color marrón rojizo en la superficie externa formada por tres bandas paralelas, de $0,2 \mathrm{~cm}$. las inferiores y $1,5 \mathrm{~cm}$. la superior. Superficie externa e interna alisadas. Pasta de excelente calidad con desgrasante pequeño apenas perceptible. Hecho a torno. Col. P. Amorós. Fig. 11.4. 


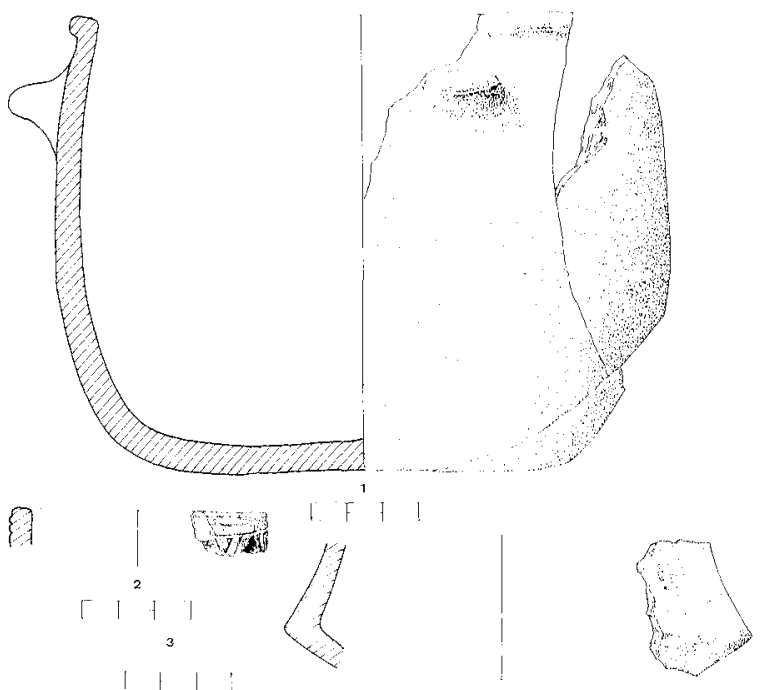

Fig. 9.

- Fragmento de cuerpo. Decoración pintada de color marrón rojizo en la superficie externa formada por dos bandas paralelas, de $0,2 \mathrm{~cm}$. la inferior y al menos $1,4 \mathrm{~cm}$. la superior. Superficie externa e interna alisadas. Pasta de excelente calidad con desgrasante fino apenas perceptible. Hecho a torno. Col. P. Amorós.

Fragmento de cuerpo, pie y base de Terra Sigillata clara D correspondiente a un mortero de la forma Hayes 91 (HAYES, 1972). Decoración estampillada de tipo geométrico en el interior. Col. P. Amorós. Fig. 11.3.

- Fragmentos de cuerpo (seis). Restos de decoración pintada de color marrón rojizo en la superficie externa. Superficie externa e interna alisadas. Pasta de excelente calidad con desgrasante fino apenas perceptible. Hecha a torno. Col. P. Amorós.
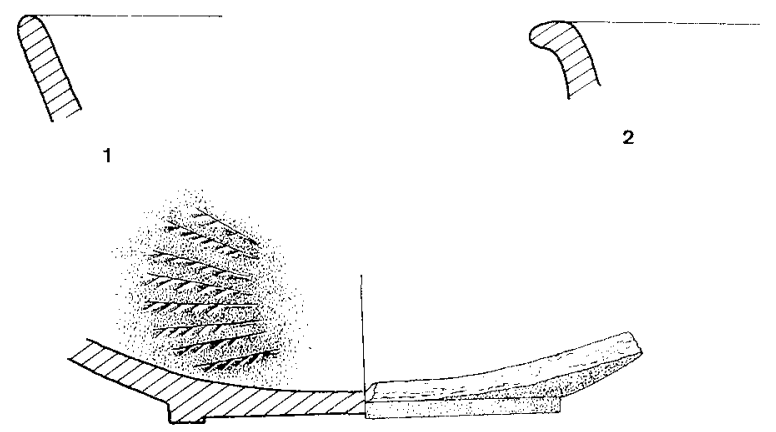

3
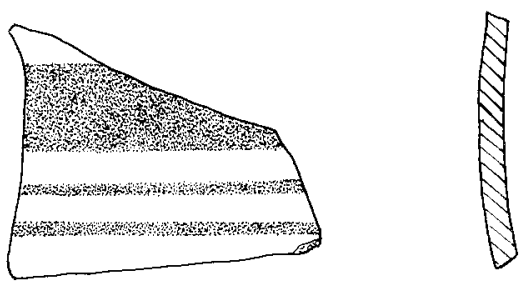

4

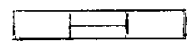

Fig. 11.

- Fragmentos informes (veintidós). Predominan las superficies externas e internas alisadas. Pastas de calidad intermedia con desgrasante fino y mediano. Col. P. Amorós.

\section{PIEDRA}

- Hacha pulimentada de forma elipsoidal. Sección de tendencia circular. Filo curvo de tendencia simétrica. Fractura en extremo distal. Ofita. Dimensiones (cm.): long. 13,2, anchura 5,4, espesor 4,2. Sector 5B. Fig. 12.1.
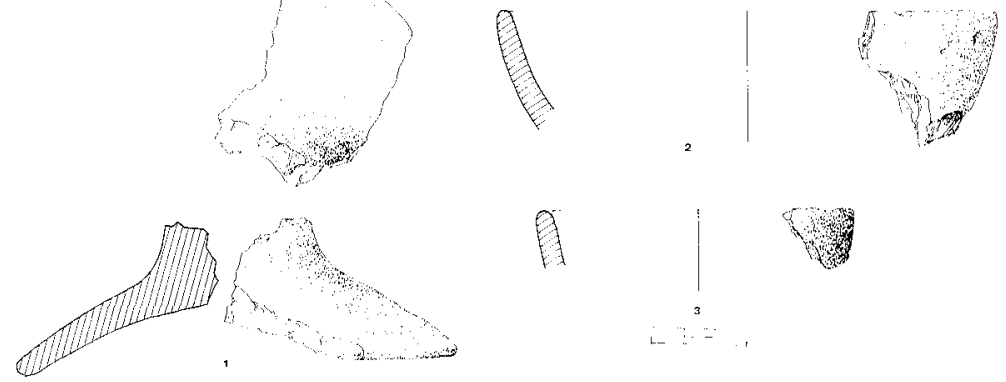

Fig. 10. 

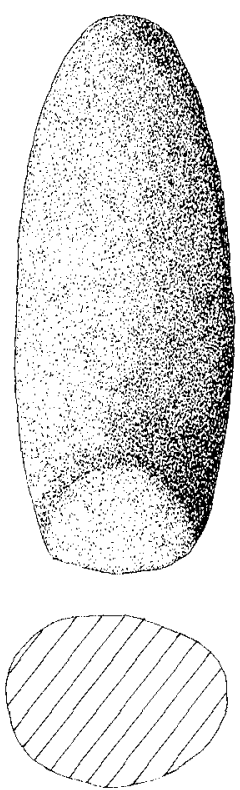

Fig. 12 .
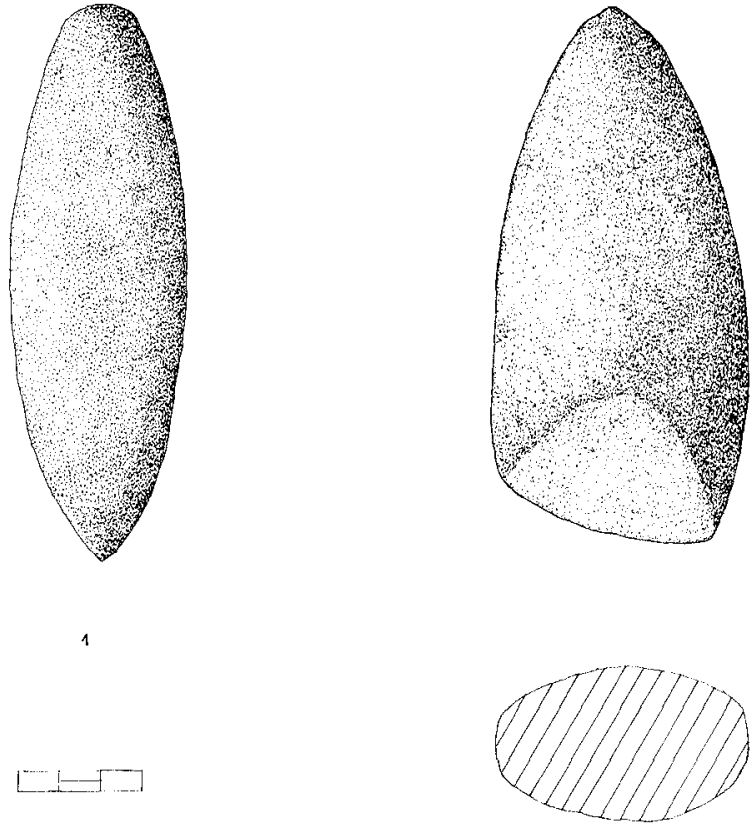

Fig. 13.

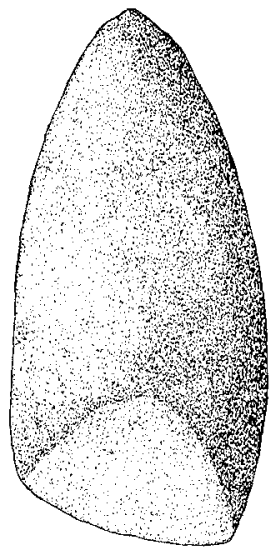

- Hacha pulimentada de tendencia triangular. Sección elipsoidal. Filo asimétrico. Pequeña fractura en extremo proximal. Ofita. Dimensiones $(\mathrm{cm}$.$) :$ long. 13, anchura 6, espesor 3,7. Sector 5A. Fig. 13.1.

- Hacha pulimentada de forma trapezoidal. Sección elipsoidal. Filo simétrico de tendencia curva. Ofita. Dimensiones (cm.): long. 10,6, anchura 6,1, espesor 3,3. Sector 4B. Fig. 14.1.

- Hacha pulimentada de forma elipsoidal con ligero rehundimiento de forma circular en extremo distal. Sección elipsoidal. Ofita. Dimensiones $(\mathrm{cm}$.$) :$ longitud 12,2, anchura 5,2, espesor 2,1. Col. P. Amorós. Fig. 16.1.

- Fragmento proximal de hacha pulimentada de filo plano. Sección elipsoidal. Ofita. Dimensiones (cm.): longitud actual 6, anchura 4,6, espesor 2,8. Col. P. Amorós. Fig. 17.2.

- Azuela pulimentada de forma trapezoidal. Sección elipsoidal. Filo curvo de tendencia simétrica. Fractura en extremo proximal y distal. Ofita. Dimensiones $(\mathrm{cm}$.): longitud 8,4 , anchura 4,6 , espesor 2,1 . Sector 5A. Fig. 17.1.

- Azuela pulimentada de forma trapezoidal. Sección plano-convexa. Filo curvo de tendencia simétrica. Muy erosionada. Ofita. Dimensiones (cm.): longitud 9,1 , anchura 5,1 , espesor 2,4 . Sector $5 A$. Fig. 18.1.
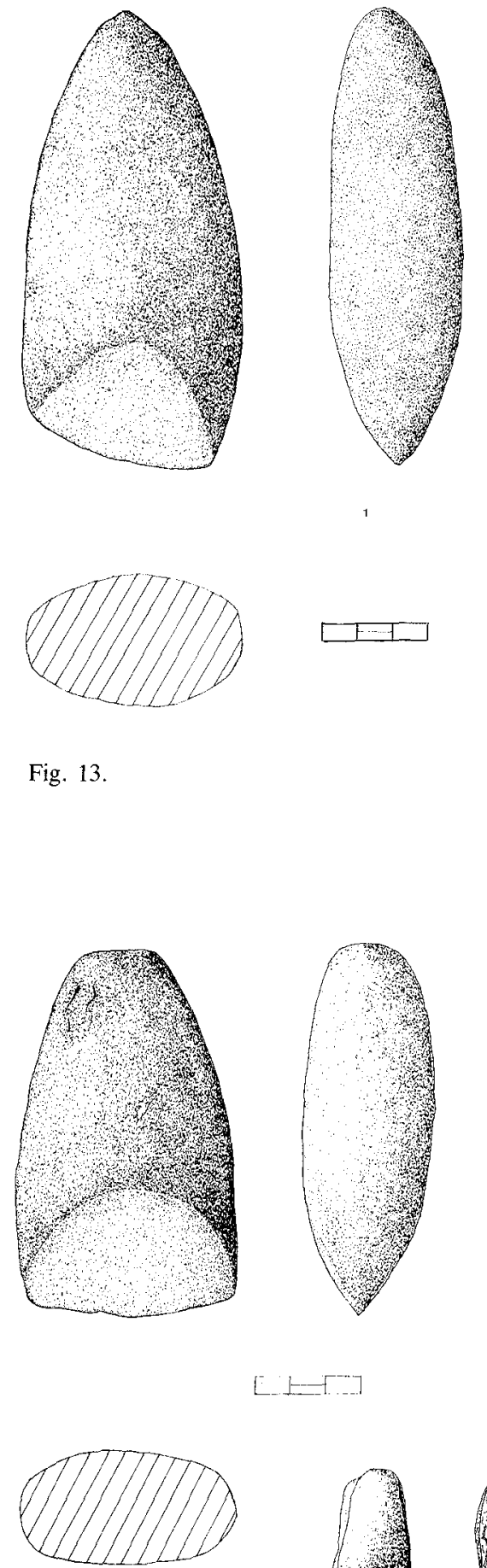


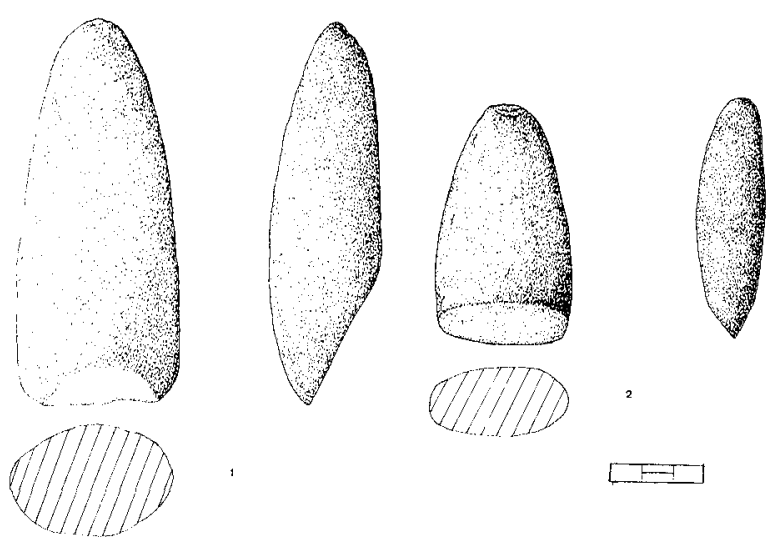

Fig. 15.

- Azuela pulimentada de tendencia triangular. Sección elipsoidal. Filo simétrico de tendencia curva. Fractura distal. Ofita. Dimensiones (cm.): longitud 12,1, anchura 3,6, espesor 3,5. Sector 5A. Fig. 15.1.

- Azuela pulimentada de forma triangular. Sección elipsoidal. Filo curvo de tendencia simétrica. Ofita. Dimensiones (cm.): longitud 7,8, anchura 4,5, espesor 2,2. Sector 4A. Fig. 15.2.

- Azuela totalmente pulida de forma trapezoidal. Sección rectangular por fractura. Filo de tendencia curva. Perfil asimétrico por fractura. Ofita. Dimensiones (cm.): longitud 3,9, anchura 2,3, espesor 1,4. Sector 4A. Fig. 13.2.

- Punta de flecha foliácea. Retoque plano, cubriente, total en una cara y parcial en la otra. Sección biconvexa. Simétrica. Sílex. Dimensiones (mm.): longitud 46, anchura 16, espesor 4. Sector 5B. Fig. 19.1.

- Punta de flecha foliácea. Retoque plano, cubriente, total por una cara y parcial por la otra. Sec-
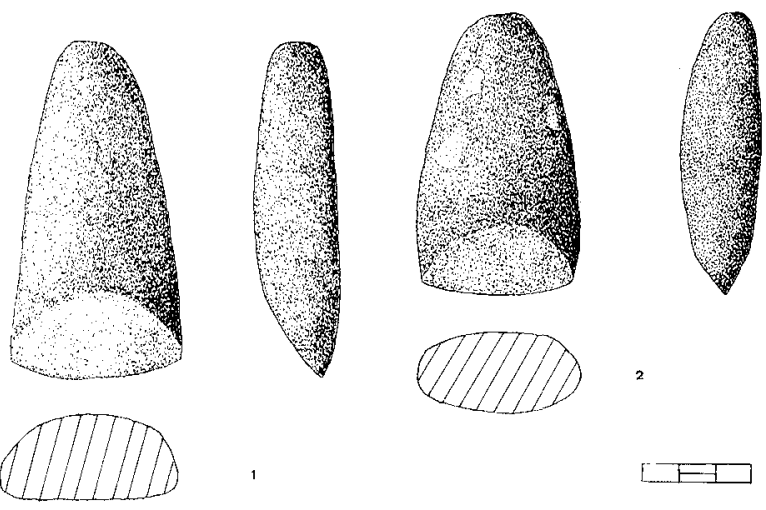

Fig. 17.
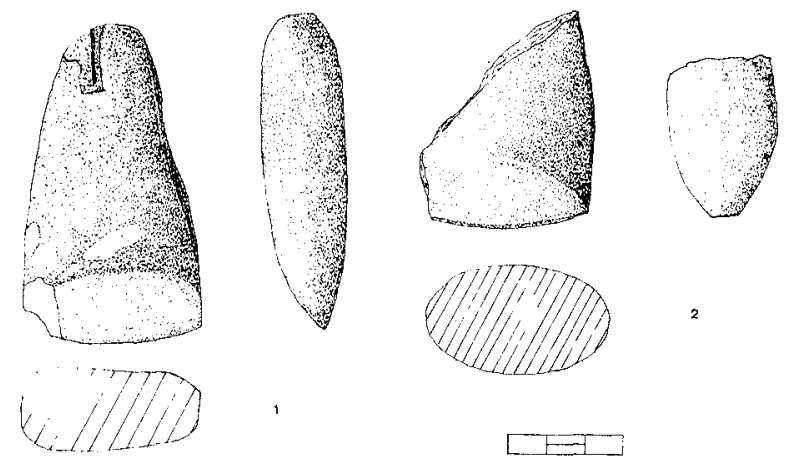

Fig. 16.

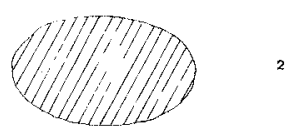

ción biconvexa. Pequeña fractura central. Simétrica. Sílex. Dimensiones (mm.): longitud 39, anchura 14, espesor 4. Sector 5B. Fig. 19.2.

- Punta de flecha romboidal. Retoque plano, cubriente y bifacial. Sección biconvexa. Fractura en extremo proximal y distal. Simétrica. Sílex. Dimensiones (mm.): longitud 24, anchura 15, espesor 3,5. Sector 5. Fig. 19.3.

- Punta de flecha foliácea. Retoque plano, cubriente y bifacial. Sección plano-convexa. Simétrica. Sílex. Dimensiones (mm.): longitud 38, anchura 19, espesor 4. Sector 4. Fig. 19.4.

- Punta de flecha foliácea. Retoque plano, cubriente y bifacial. Sección biconvexa. Simétrica. Sílex. Dimensiones (mm.): longitud 35, anchura 13, espesor 3,5. Sector 5A. Fig. 19.5.

- Punta de flecha de pedúnculo y aletas agudas asimétricas (una de ellas muy desarrollada). Retoque plano, cubriente y bifacial. Ejes denticulados. Sección plano-convexa. Pequeña fractura en extremo distal. Asimétrica. Sílex. Dimensiones (mm.): longitud 29, anchura 15, espesor 4,5. T. O. Fig. 19.6.

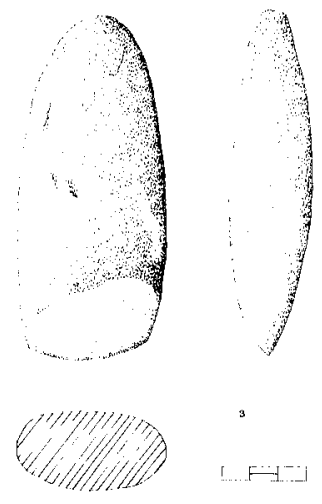

Fig. 18. 

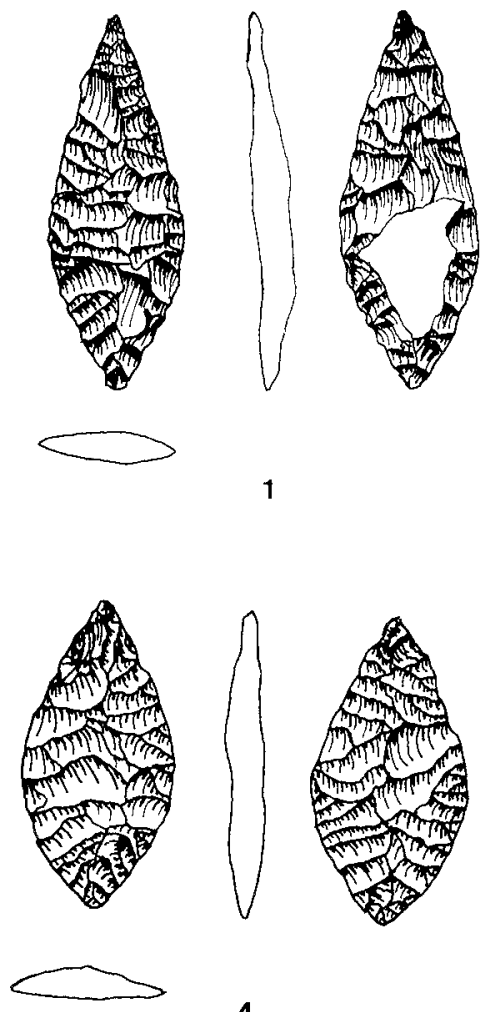

4
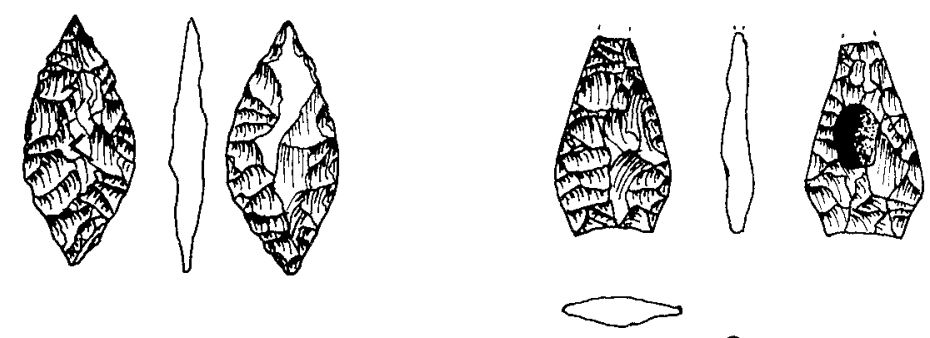

3
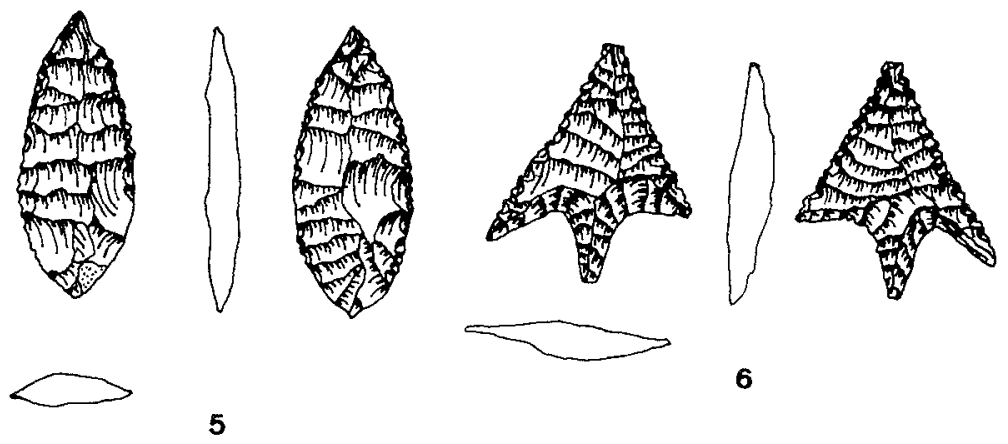

5
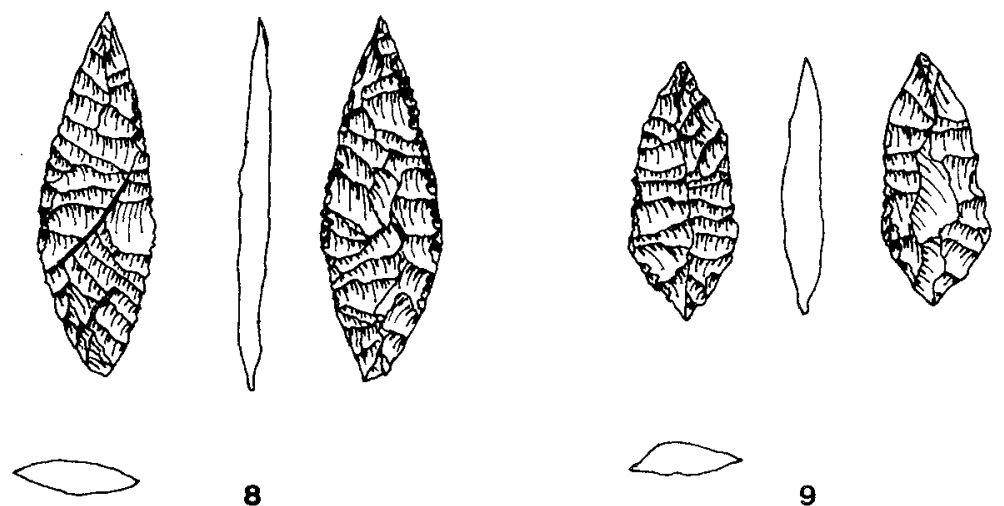

8

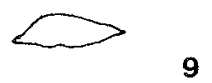

Fig. 19.

- Punta de flecha foliácea. Retoque plano, cubriente y bifacial. Ejes denticulados. Sección biconvexa. Fractura en extremo proximal. Simétrica. Sílex. Dimensiones $(\mathrm{mm})$ : longitud 52, anchura 16 , espesor 4. Sector 5B. Fig. 19.7.
- Punta de flecha foliácea. Retoque plano, cubriente y bifacial. Ejes denticulados. Sección biconvexa. Pequeña fractura en extremo proximal. Simétrica. Sílex. Dimensiones (mm): longitud 45, anchura 15 , espesor 4,5 . Sector 5B. Fig. 19.8 . 

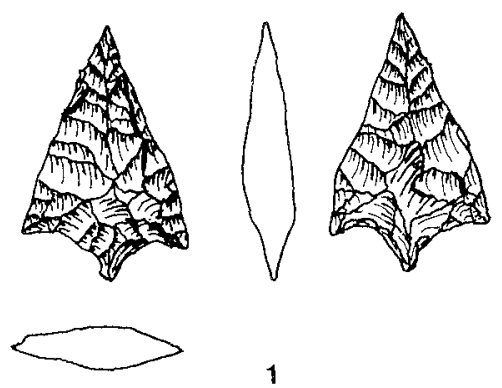

1
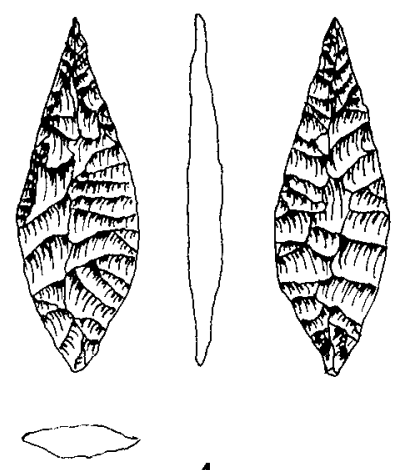

4
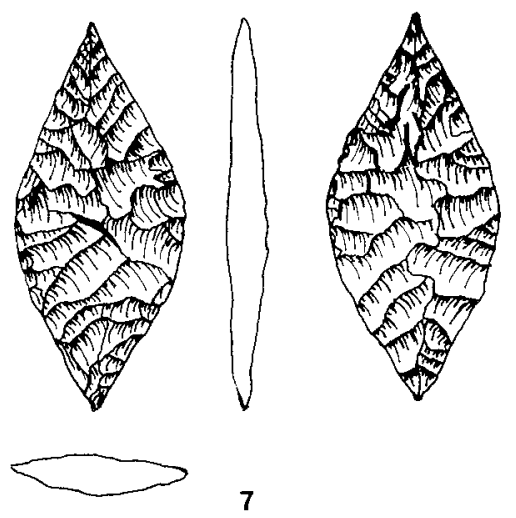

7
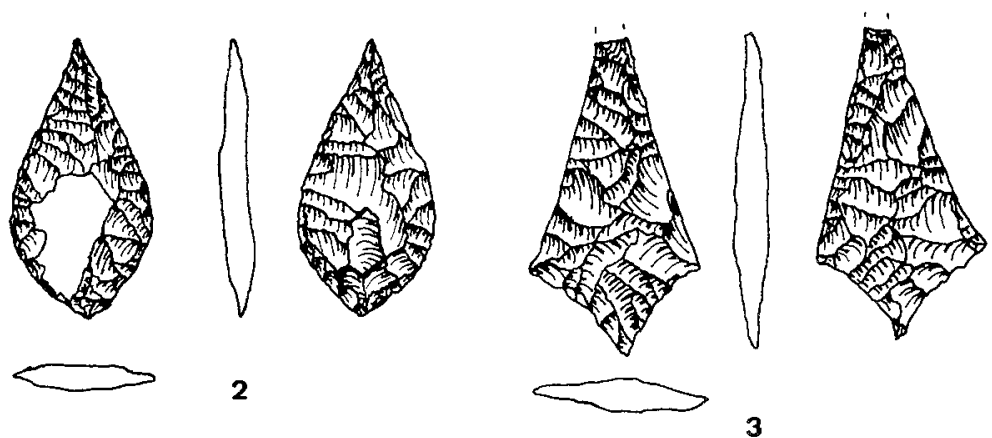

3
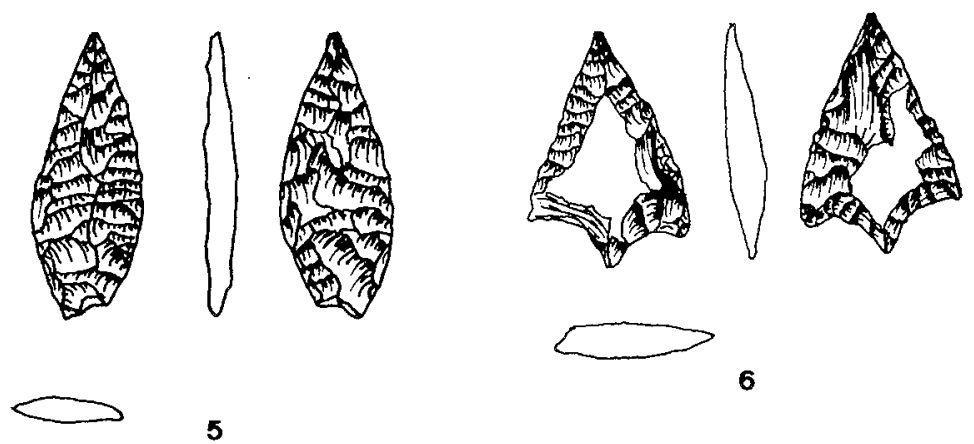

5
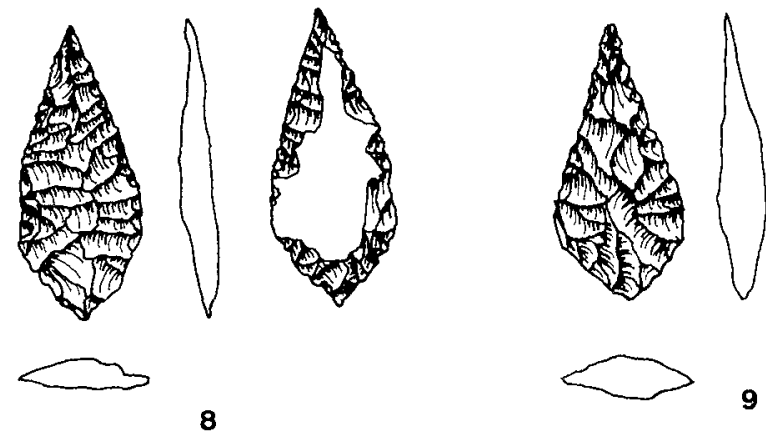

Fig. 20 .

- Punta de flecha foliácea. Retoque plano, cubriente, total en una cara y parcial en la otra. Sección biconvexa. Simétrica. Sílex. Dimensiones $(\mathrm{mm})$ : longitud 32, anchura 14, espesor 4. Sector 5B. Fig. 19.9.

- Punta de flecha de pedúnculo y aletas agudas poco desarrolladas. Retoque plano, cubriente y bifacial. Sección biconvexa. Asimétrica. Silex. Dimensiones (mm): longitud 32 , anchura 21 , espesor 5,5. Sector 5B. Fig. 20.1.

- Punta de flecha foliácea. Retoque plano, cubriente, total en una cara y parcial en la otra. Sec- ción biconvexa. Simétrica. Sílex. Dimensiones (mm): longitud 35, anchura 18, espesor 3. Sector 5B. Fig. 20.2 .

- Punta de flecha de pedúnculo y aletas agudas incipientes. Retoque plano, cubriente y bifacial. Sección plano-convexa. Fractura en extremo distal. Asimétrica. Sílex. Dimensiones ( $\mathrm{mm}$ ): longitud 40, anchura 22, espesor 3,5. Sector 5B. Fig. 20.3.

- Punta de flecha foliácea. Retoque plano, cubriente y bifacial. Sección biconvexa. Simétrica. Sílex. Dimensiones (mm): longitud 45 , anchura 15 , espesor 4. Sector 5A. Fig. 20.4. 

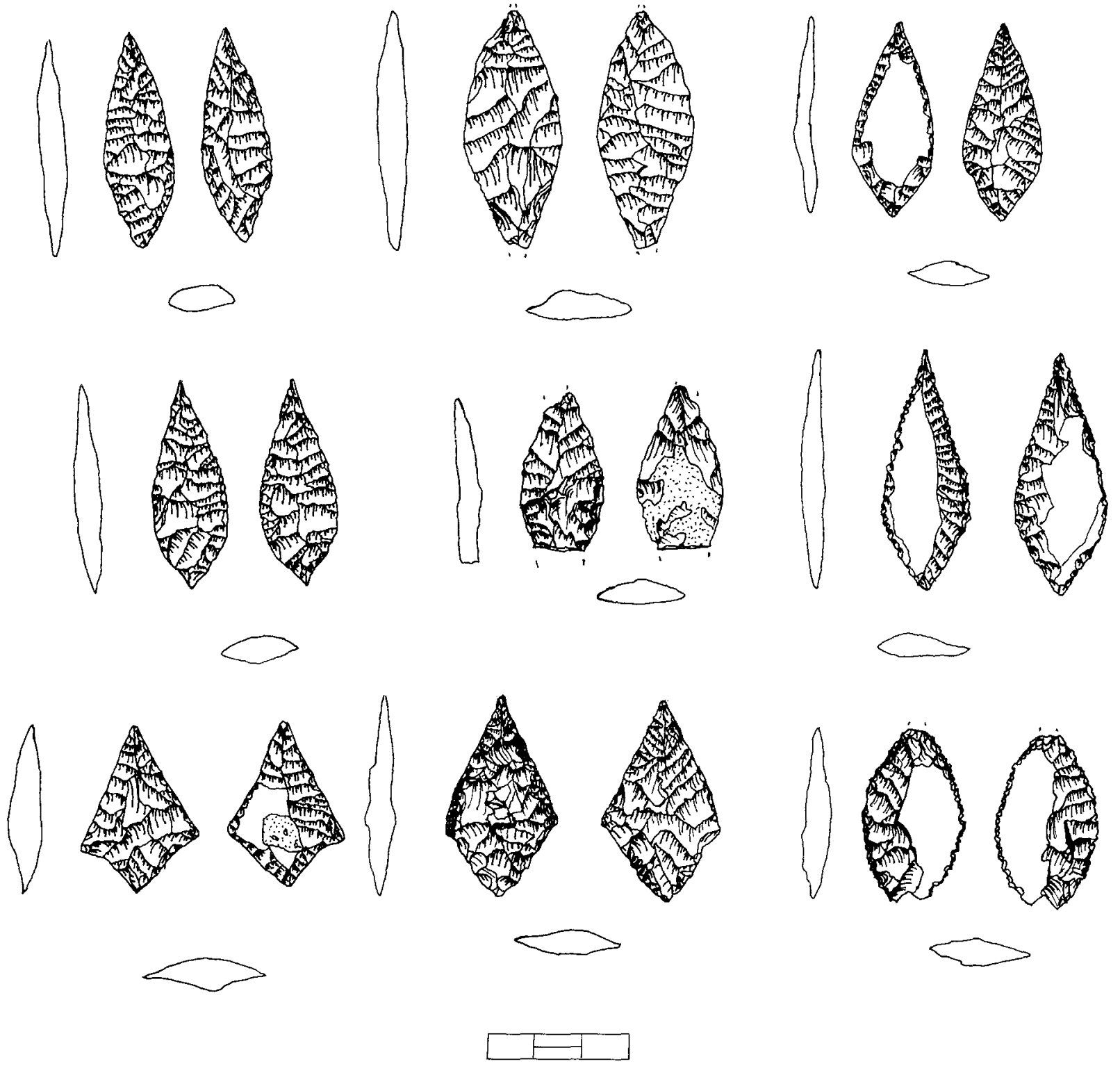

Fig. 21 .

- Punta de flecha foliácea. Retoque plano, cubriente y bifacial. Sección biconvexa. Fractura en extremo proximal. Asimétrica. Sílex. Dimensiones (mm): longitud 34, anchura 14, espesor 3. Sector 4. Fig. 20.5.

- Punta de flecha con pedúnculo y aletas agudas, poco desarrollada una e incipiente la otra. Retoque plano, cubriente y parcial en ambas caras. Sección biconvexa. Asimétrica. Sílex. Dimensiones $(\mathrm{mm})$ : longitud 30 , anchura 20 , espesor 4,5. Sector 5B. Fig. 20.6 .
- Punta de flecha foliácea. Retoque plano, cubriente y bifacial. Sección plano-convexa. Simétrica. Sílex. Dimensiones (mm): longitud 49, anchura 22, espesor 5. Sector 5B. Fig. 20.7.

- Punta de flecha foliácea. Retoque plano, cubriente, total en una cara y parcial en la otra. Sección plano-convexa. Ejes denticulados. Simétrica. Sílex. Dimensiones (mm): longitud 38, anchura 17 , espesor 4. T. O. Fig. 20.8.

- Punta de flecha foliácea. Retoque plano, cubriente y bifacial. Sección biconvexa. Ejes denticu- 

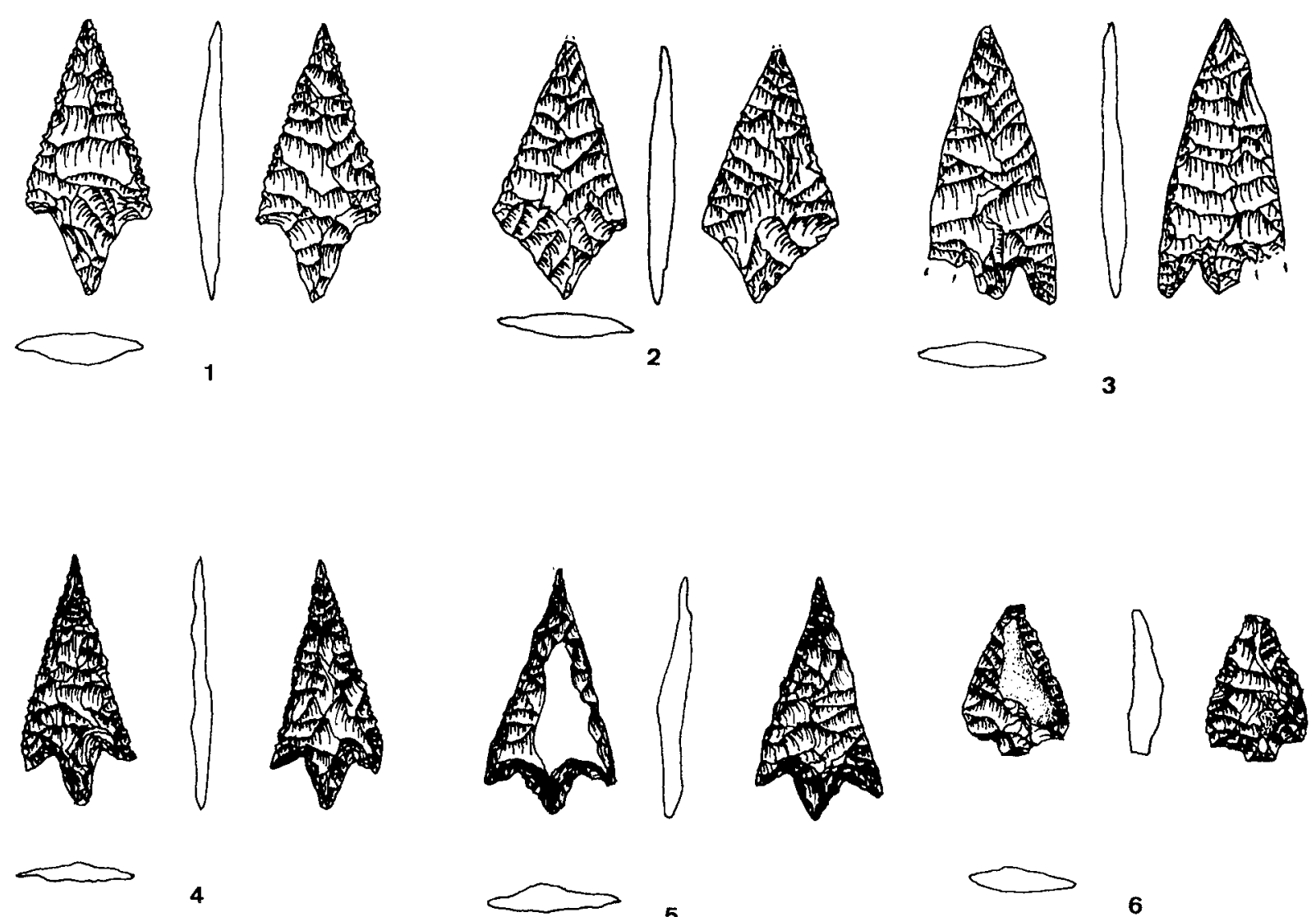

1

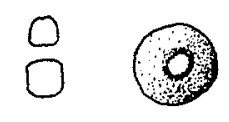

8
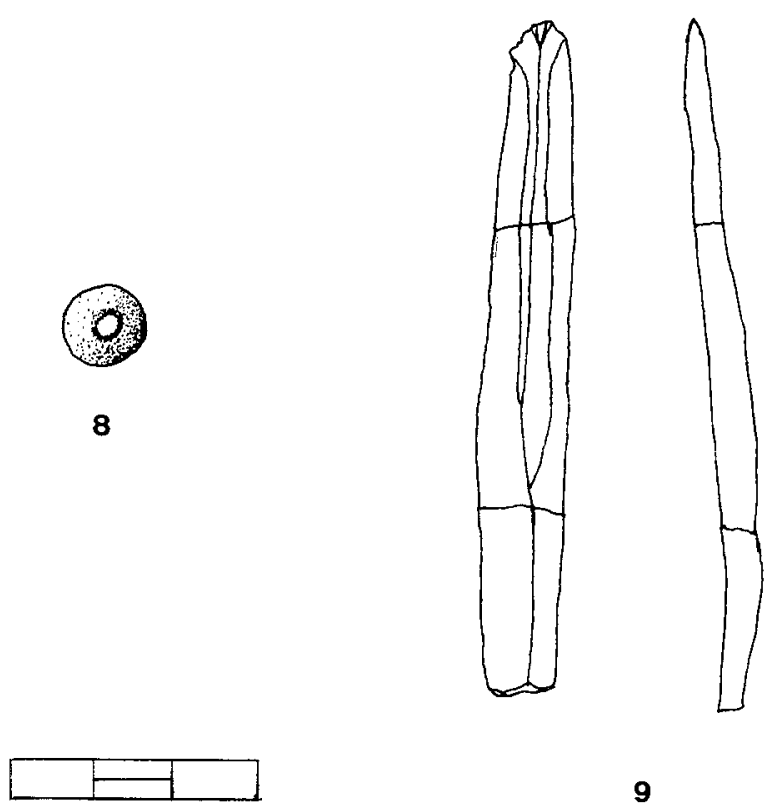

Fig. 22. 


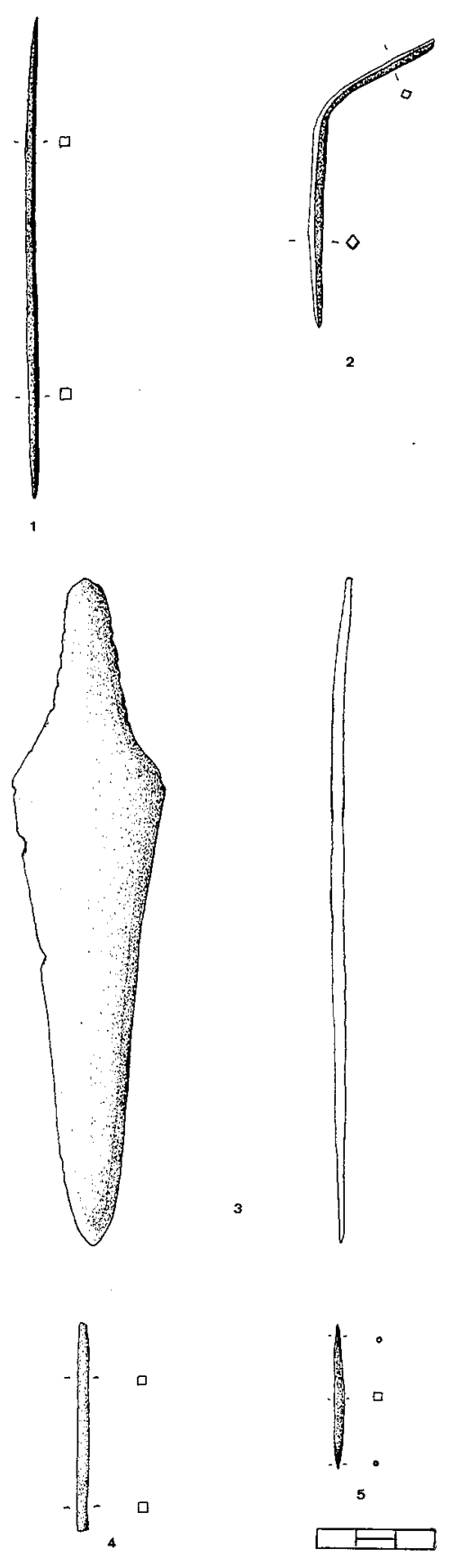

lados. Simétrica. Sílex. Dimensiones (mm): longitud 25, anchura 17, espesor 5. Sector 4. Fig. 20.9.

- Punta de flecha de pedúnculo desarrollado y aletas agudas incipientes. Retoque plano, cubriente y bifacial. Sección biconvexa. Simétrica. Sílex. Dimensiones (mm): longitud 42, anchura 19, espesor 4,5. Sector 4. Fig. 22.1.

- Punta de flecha romboidal con aletas incipientes. Retoque plano, cubriente y bifacial. Sección biconvexa. Pequeña fractura en extremo distal. Ejes denticulados (poco marcados). Sílex. Dimensiones (mm): longitud 38, anchura 21, espesor 4 . Sector 4. Fig. 22.2.

- Punta de flecha de pedúnculo y aletas agudas desarrolladas. Retoque plano, cubriente y bifacial. Sección biconvexa. Fractura en una de las aletas. Simétrica. Sílex. Dimensiones $(\mathrm{mm})$ : longitud 41, anchura 19, espesor 3,5. Sector 4A. Fig. 22.3.

- Punta de flecha foliácea. Retoque plano, cubriente y bifacial. Sección biconvexa. Ejes denticulados. Sílex. Dimensiones (mm): longitud 37, anchura 14,5, espesor 5. Col. P. Amorós. Fig. 21.1.

- Punta de flecha foliácea. Retoque plano, cubriente y bifacial. Sección biconvexa. Pequeña fractura en extremo distal. Sílex. Dimensiones (mm.): longitud 45, anchura 18,5, espesor 5,5. Col. P. Amorós. Fig. 21.2.

- Punta de flecha foliácea. Retoque plano, cubriente y bifacial. Sección plano-convexa. Sílex. Dimensiones (mm.): longitud 41 , anchura 13,6 , espesor 5. Col. P. Amorós. Fig. 21.3.

- Punta de flecha foliácea. Retoque plano, invasor y bifacial. Sección biconvexa. Ejes denticulados. Silex. Dimensiones (mm.): longitud 47, anchura 18, espesor 4,5. Col. P. Amorós. Fig. 21.4.

- Punta de flecha foliácea. Retoque plano, cubriente, total por una cara y parcial por la otra. Sección biconvexa. Fractura en ambos extremos. Sílex. Dimensiones (mm.): longitud 38, anchura 15, espesor 4. Col. P. Amorós. Fig. 21.5.

- Punta de flecha foliácea. Retoque plano, cubriente y bifacial. Sección biconvexa. Pequeña fractura en extremo proximal y distal. Ejes denticulados. Sílex. Dimensiones (mm.): longitud 34, anchura 16,5, espesor 4,5. Col. P. Amorós. Fig. 21.6.

- Punta de flecha foliácea. Retoque plano, cubriente, total por una cara y parcial por la otra. Sección plano-convexa. Pequeña fractura en extremo proximal; gran fractura en extremo distal. Sílex. Dimensiones (mm.): longitud 30, anchura 16 , espesor Fig. 23. 
- Punta de flecha romboidal con aletas incipientes. Retoque plano, cubriente y bifacial. Sección biconvexa. Sílex. Dimensiones (mm.): longitud 38, anchura 22, espesor 5,5. Col. P. Amorós. Fig. 21.8.

- Punta de flecha con pedúnculo y aletas poco desarrolladas. Retoque plano, cubriente, total en una cara y parcial en la otra. Restos de córtex en una cara. Sección biconvexa. Sílex. Dimensiones (mm.): longitud 31,5, anchura 22, espesor 6. Col. P. Amorós. Fig. 21.9.

- Punta de flecha con pedúnculo y aletas marcadas. Retoque plano, cubriente y bifacial. Sección biconvexa. Ejes denticulados. Sílex. Dimensiones (mm.): longitud 38, anchura 17, espesor 3,5. Col. P. Amorós. Fig. 22.9.

- Punta de flecha con pedúnculo y aletas marcadas. Retoque plano, cubriente por una cara e invasor por la otra. Sección biconvexa. Sílex. Dimensiones (mm.): longitud 37, anchura 19,5, espesor 4,5. Col. P. Amorós. Fig. 22.5.

- Punta de flecha con pedúnculo y aletas de diferente orientación (una aguda y la otra obtusa). Retoque plano, cubriente por una cara e invasor por la otra. Sección biconvexa. Fractura distal y proximal. Sílex. Dimensiones (mm.): longitud 23,5, anchura 16,5, espesor 4,5. Col. P. Amorós. Fig. 22.6.

- Extremo distal de punta de flecha. Retoque plano cubriente bifacial. Sector 2. Fig. 22. 7.

- Lámina de sección trapezoidal. Sílex. Dimensiones (cm.): longitud 8,3, anchura 1,2, espesor 0,5 . Sector 5A. Fig. 22.9.

- Laminita. Retoque marginal bilateral. Sección plano-convexa. Sílex. Dimensiones (mm.): longitud 41, anchura 12, espesor 4. Col. P. Amorós.

- Laminita. Sin retoque. Fractura distal. Sílex. Dimensiones (mm.): longitud 30, anchura 14, espesor 4. Col. P. Amorós.

- Lascas (nueve). Sin retoque. Sílex. Col. P. Amorós.

\section{Metal}

- Puñal de lengüeta dentada. Nervadura central marcada en hoja y lengüeta. La hoja presenta dos escotaduras modernas en un eje mientras que la lengüeta ofrece parte de sus bordes dentados. Composición: $\mathrm{Cu} 99,08 \%$ As 0,92\% (3). Peso 52 g. Excelente estado de conservación. Dimensiones (cm.): longitud 16,9, anchura 3,8, espesor 0,35 . Col. P. Hernández. Fig. 23.3.
- Punzón biapuntado de sección cuadrada. Composición: Cu 100\% Peso 0,76 g. Excelente estado de conservación. Dimensiones (cm.): longitud 3,6, anchura 0,3, espesor 0,3. Sector 5B. Fig. 23.5 .

- Punzón biapuntado de sección cuadrada. Composición: Cu 95,15\% As 4,85\%. Peso 5,6 g. Excelente estado de conservación. Dimensiones (cm.): longitud 12,2, anchura 0,3 , espesor 0,3 . Sector 5B. Fig. 23.1.

- Fragmento de punzón apuntado. Sección cuadrada. Fractura en extremo proximal. Composición: $\mathrm{Cu} 92,80 \%$ Sn $6,23 \%$ Si $0,28 \%$ Sulfuro $0,69 \%$. Buen estado de conservación. Peso $3 \mathrm{~g}$. Dimensiones (cm.): longitud 8,9 , anchura 0,25 , espesor 0,25. Col. P. Hernández. Fig. 23.2.

- Punzón. Sección cuadrada. Fracturado en los dos extremos. Composición: Cu 98,24\% As 1,76\%. Buen estado de conservación. Peso 1,7 g. Dimensiones (cm.): longitud 5,2, anchura 0,3 , espesor 0,3 . Col. P. Hernández. Fig. 23.4.

- Anillo o arete con extremos separados por fractura. Sección circular. Señales de oxidación incipiente. Peso 0,6 g. Dimensiones (cm.): diámetro 2,4, espesor 0,15. Col. P. Hernández. Fig. 23.6.

- Aguja con canal interior formado por una estrecha lámina enrrollada sobre sí misma. Sección circular. Bronce. Peso 0,7 g. Dimensiones (mm.): longitud 4, espesor 0,25. Col. P. Amorós.

\section{Adorno}

- Cuenta de collar discoidal con perforación central. Sección elipsoidal alargada. Piedra verde. Dimensiones (mm.): diámetro 10, espesor 4. Col. P. Amorós. Fig. 22.8.

\section{VALORACIÓN CULTURAL}

Las cuevas de enterramiento múltiple son, sin duda, uno de los elementos más característicos de la Prehistoria del País Valenciano. Este fenómeno, cuyo origen se remonta al Neolítico Final, se ha utilizado para caracterizar la Edad del Cobre en esta zona dada la tradicional escasez de datos sobre el hábitat, conocido mejor por trabajos recientes (BERNABEU et ALII, 1988; BENITO, 1989).

Los estudios de E. Pla (1954), M. Tarradell (1963) y E. Llobregat (1966) incidieron en la problemática de este tipo de yacimientos, discusión que 
se mantiene vigente en la actualidad pese a los descubrimientos de nuevos asentamientos, fruto, en la mayoría de los casos, de excavaciones clandestinas. Sólo algunos de los estudios realizados revestían un cierto vigor científico.

En las comarcas circundantes, la Edad del Cobre ha sido estudiada con relativa profusión y desigual fortuna. Los trabajos de J. Aparicio (1981) sobre Bañeres y de J. M. ${ }^{a}$ Soler sobre Villena (1981) sirvieron para completar las antiguas noticias de yacimientos sepulcrales en estas zonas, al tiempo que A. González $(1973 ; 1982)$, F. Cerdá (1983) y en especial J. Soler Díaz (1985), publicaban nuevos yacimientos o materiales de los ya conocidos de la Foia de Castalla, con especial atención a los de El Fontanal (Onil).

La excavación de la Cova del Cantal viene a significar una nueva aportación al estudio del fenómeno del enterramiento múltiple en esta zona. El yacimiento, enclavado en el extremo NW de la Foia de Castalla, en una sierra junto a la entrada del Puerto de Biar, presenta una planta irregular con forma de «u» y dos bocas orientadas al SW. En ella se inhumaron con seguridad nueve individuos (a juzgar por los cráneos), cuestión que se tratará con profundidad en el trabajo correspondiente. En la zona excavada por nosotros el amontonamiento irregular de huesos es la única forma de deposición registrada, no encontrando en ningún momento una clara disposición anatómica.

El análisis de los materiales de la Cova del Cantal es especialmente interesante debido a que se trata de un conjunto cerrado de carácter eminentemente votivo. De forma especial destaca el Sector 5, ya que es el único en el que se ha podido reconstruir íntegramente la disposición de los ajuares y restos humanos, aportando comparativamente el mayor y más significativo conjunto de materiales: la excavación de esta zona ha permitido reconstruir siete formas cerámicas (Fig. 4.1 y 4.2; Fig. 5.1 y 5.2; Fig. 6.1; Fig. 7.1 y 7.2), proporcionando además trece puntas de flecha (Fig. 19.1, 19.2, 19.5, 19.6, 19.7, 19.8, 19.9; Fig. 20.1, 20.2, 20.3, 20.4, 20.6, 20.7), dos hachas (Fig. 12.1; Fig. 13.1), tres azuelas (Fig. 15.1; Fig.18.1: Fig. 17.1) y dos punzones de metal (Fig. 23.1 y 23.5).

El resto de los materiales de excavación contribuye al estudio global de la cueva. Por último, otros que pudieran haber tenido gran significación de haberse encontrado «in situ», no pueden ser considerados de igual forma porque proceden de colec- ciones privadas y de la excavación de zonas alteradas. A pesar de ello, no dejan de ser importantes y pueden servir para matizar o concretar la valoración general. No en vano hemos podido estudiar cinco formas cerámicas más, veintiuna puntas de flecha, dos hachas, dos azuelas, una cuenta de collar, un puñal de lengüeta y dos punzones de metal.

En la cerámica predominan las formas esféricas $(54,5 \%)$, en las que observamos algunas variantes. A éstas corresponden bordes mayoritariamente rectos y entrantes, seguidos de los exvasados, con extremos principalmente convexos (encontrando también los apuntados, planos y biselados). Las bases más numerosas son las convexas, destacando el alto porcentaje de las planas. Los elementos de aprehensión más comunes son las asas de lengüeta, siendo menos frecuentes las de cinta horizontal.

Las superficies alisadas son las más generalizadas, tanto por el interior como por el exterior de la pieza. Un tercio de las externas están bruñidas, descendiendo ligeramente el número de las internas. La pasta es cuidada en un 73,6\% de los casos y está compuesta normalmente por desgrasantes de tamaño pequeño y mediano.

Son mayoritarias las asociaciones entre bordes entrantes y extremos convexos y la de bordes rectos y extremos apuntados, así como las superficies alisadas por las dos caras y las pastas cuidadas con desgrasantes pequeño y mediano. Un $20 \%$ de los casos tiene ambas superficies bruñidas, pasta cuidada y desgrasante pequeño o mediano.

Las formas esféricas con bases planas se dan en un $40 \%$ de las ocasiones (un $30 \%$ son formas de tendencia esférica); la mitad de ellas tienen asas de lengüeta. En lo que se refiere a las bases, cabría destacar las convexas, seguidas de cerca por las planas o tendencia a planas. Además hay un pie que corresponde a la copa antes descrita.

Las formas más representadas tienen paralelos claros con el mundo característico de las cuevas de enterramiento calcolíticas de la zona. Se trata fundamentalmente de la forma esférica de base plana o de tendencia plana y de la elipsoide horizontal con borde exvasado y base convexa o de tendencia plana (Fig. 4.1; Fig. 5.2; Fig. 8.1 y 8.2; Fig. 10.2) piezas con una gran difusión. Sirva como ejemplo los cercanos paralelos existentes en yacimientos como la Cova del Sol (APARICIO et ALII, 1981), la Cueva de las Lechuzas y las cuevas Occidental y Oriental del Peñón de la Zorra (SOLER, 1981). Más extrañas son formas como la cilíndrica de base con- 
vexa y pequeño tamaño (Fig. 7.1) o la globular de tamaño medio con dos asas de lengüeta en el tercio inferior (Fig. 4.2), halladas en la excavación en contextos claramente enmarcables en el Calcolítico Pleno o momentos avanzados de éste (Sector 5). Igualmente extraño al mundo de las cuevas de enterramiento de este período y zona, es un pie de copa perteneciente a los materiales de los coleccionistas (Fig. 10.1) posiblemente relacionado con la Edad del Bronce, en la que tenemos numerosos ejemplos, y presente también en las cuevas de enterramiento relacionadas con el H. C. T. como la Cova dels Gats de Alcira -en la que J. Bernabeu (1984) dice que puede haber también materiales de la Edad del Bronce - y en contextos del Calcolítico de Andalucía Occidental (MARTIN, 1986). Llama la atención el asa de cinta horizontal cercana al borde de una vasija hallada en el Sector 5 (Fig. 6.1), de la que no hemos encontrado ningún paralelo cercano. Especial mención merece también el fragmento de cerámica con decoración de tipo Campaniforme (Fig. 9.2), que nos ofrecería un momento cronológico de referencia a tener en cuenta, sobre todo por la existencia de otros objetos que apoyan esta cronología. La presencia de una vasija carenada (Fig. 9.3) abogaría, al menos en principio, por su adscripción a la Edad del Bronce. Parece claro, por otra parte, que las formas cerámicas de este yacimiento no son semejantes en líneas generales a las más abiertas encontradas en La Macolla de Villena (GUITART, 1989) ni a las de otros yacimientos recientemente actualizados (BERNABEU et ALII, 1988).

Hemos podido estudiar treinta y cuatro puntas de flecha, doce de las cuales pertenecen a los coleccionistas. Entre ellas destacan las foliáceas $(60,6 \%)$ sobre las de pedúnculo y aletas $(30,4 \%)$ y las romboidales. El retoque, siempre plano, es cubriente y bifacial en dos tercios de las piezas, total en una cara y parcial en la otra en siete casos y parcial en ambas en uno. Su sección es mayoritariamente biconvexa, registrando también la variante planoconvexa. Nueve de ellas tienen ejes denticulados.

En cuanto a las dimensiones, la longitud máxima de estas puntas es de 54 milímetros, la mínima de 23,5 y la media de 36,7 . La mayor anchura registrada es de $22 \mathrm{~mm}$., la menor de 13 y la media de 17,4. El espesor máximo es de $8 \mathrm{~mm}$., el mínimo de 3 y el medio de 4,5 .

La punta de flecha tipo de este yacimiento sería, pues, de sílex, foliácea, con retoque plano, cu- briente y bifacial, sección biconvexa, matriz laminar o indeterminada y de $36,7 \times 17,4 \times 4,5 \mathrm{~mm}$. de longitud, anchura y espesor respectivamente.

Los tipos presentados en la Cova del Cantal son semejantes a las de la Cova de la Barsella, El Fontanal y La Pastora (SOLER DÍAZ, 1988). Así, la matriz nodular está representada en un porcentaje mínimo, la mayoría de las puntas tienen sección transversal biconvexa, un alto porcentaje de retoque plano cubriente bifacial y una relación longitudanchura superior a 2 .

De las tres láminas estudiadas, destacaremos el pequeño tamaño $(9,3 \mathrm{~cm}$. de longitud máxima, 1,2 ó $1,4 \mathrm{~cm}$. de anchura y 0,4 ó $0,5 \mathrm{~cm}$. de espesor) a la vez que el retoque marginal bilateral de una de ellas. De igual forma debería señalarse la presencia mayoritaria de secciones trapezoidales (en dos casos) frente a la plano-convexa.

Las puntas de flecha que forman el ajuar de la Cova del Cantal son bastante comunes en yacimientos paralelos, abundantes en la zona cercana geográficamente. Por el contrario, tipos que habitualmente existen en otras cuevas no están en la que estudiamos: las puntas de flecha claramente cruciformes, normales en yacimientos de Villena (SOLER, 1981), Bañeres (APARICIO et ALII, 1981), o la Foia de Castalla con El Fontanal (SOLER DÍAZ, 1988); puntas de flecha foliáceas, o romboidales con aletas inversas de las dos zonas citadas en primer lugar; y las de base cóncava, relativamente escasas (dos ejemplares) en Bañeres (APARICIO et ALII, 1981), no existen en el caso de la Cọa del Cantal.

Las puntas de pedúnculo y aletas agudas, normalmente asociadas a artefactos metálicos u objetos de adorno del H. C. T. (SOLER DÍAZ, 1988) y presentes en la Cova del Cantal, ayudan a determinar cronológicamente el yacimiento, bien entendido que este tipo de puntas no es exclusivo del momento campaniforme. Debemos tener en cuenta que fueron encontradas por los clandestinos y no están presentes en el Sector 5. El resto de puntas de flecha presenta una cronología muy amplia que incluye en general las fechas que proponemos para la necrópolis, si bien son más comunes del período conocido tradicionalmente como Eneolítico, hecho del que tenemos infinidad de ejemplos.

Hachas y azuelas se encuentran representadas por igual en el yacimiento, aunque dos de las cinco hachas pertenecen a colecciones privadas. 
Atendiendo a la forma de las hachas, cabría decir que dos de ellas son elipsoidales (Fig. 12.1; Fig. 16.1), una de tendencia triangular (Fig. 13.1), siendo la sección elipsoide en cuatro ocasiones y de tendencia circular en una. El tipo de filo es muy variado: contamos con un ejemplo de filo curvo, otro de tendencia curva y otro plano. En lo referente a las dimensiones, la longitud mayor es de 13,2 mm., la menor de 10,6 y la media de 12,2 , siendo la anchura máxima de $6,4 \mathrm{~mm}$., la mínima de 4,6 y la media de 5,6; el espesor máximo es de 4,2 mm., el mínimo de 3,6 y el medio de 4 .

En las azuelas la forma predominante es la trapezoidal, representada en tres casos (Fig. 17.1; Fig. 18.1; Fig.14.1), frente a uno triangular (Fig. 15.2) y otro de tendencia triangular (Fig. 15.1). La sección siempre es elipsoidal. El filo, curvo o de tendencia curva. Por lo que a las dimensiones respecta, la longitud mayor es de $12,1 \mathrm{~cm}$., la menor 7,8 $(3,9)$ (1) y la media $9,2(8,2)$. La anchura máxima es de $5,1 \mathrm{~cm}$., la mínima de $3,6(2,3)$ y la media de 4,4 (4). El espesor mayor es de $3,5 \mathrm{~cm}$., el menor de $2,1(1,4)$ y el medio de $3,1(2,9)$.

Comparando ambos tipos de útiles destaca la forma trapezoidal o triangular de las azuelas frente a la elipsoidal mayoritaria de las hachas, la sección elipsoidal en ambas, la tendencia general de filo curvo en las azuelas, la variedad que presentan las hachas, y el menor tamaño general de las primeras frente a las segundas. Así el hacha tipo tendría forma elipsoidal, al igual que la sección, filo variable y $12,1 \times 5,6 \times 4 \mathrm{~cm}$. La azuela tipo sería de forma de tendencia trapezoidal, sección elipsoidal, filo curvo y $9,2(8,2) \times 4,45(4) \times 2,55(2,32) \mathrm{cm}$.

Si contrastamos el número y características de los útiles de piedra pulida de la Cova del Cantal con los hallados en yacimientos cercanos, resulta que en estos últimos hay bastantes menos ejemplos. Así en El Fontanal de Onil sólo se han encontrado dos hachas (CERDA, 1983) y una en el Mas de Felip de Ibi (GONZÁLEZ, 1973). Pocas son también las de Bañeres, destacando las nueve hachas y dos azuelas de la Cova de la Reliquia (APARICIO et ALII, 1981). De Villena sólo conocemos las dos hachas de la Cueva de las Lechuzas (SOLER, 1981; 1986), tó-

(1) El análisis de las azuelas presenta el caso especial de la existencia de una de reducidas dimensiones, que provoca resultados totales inferiores en las medidas. Por tanto incluiremos entre paréntesis, donde sea preciso, el valor alcanzado por el conjunto teniendo en cuenta esta azuela. nica que se mantiene en los yacimientos del Vinalopó (HERNÁNDEZ, 1982). En Valencia, la Covacha Sepulcral del Camí Real de Albaida (BALLESTER, 1928) con ocho hachas y dos azuelas o la Cova Santa de Vallada con cuatro hachas (MARTÍ, 1981).

Sorprende la exigüa representación de azuelas en los yacimientos estudiados, que en la Cova del Cantal llegan al 50\% de los útiles de piedra pulida. La materia prima con la que se ha realizado, ofita en todas (2), no resulta extraña en yacimientos de este tipo. Encontramos en Villena (SOLER, 1981) y en la loma de los Peregrinos de Alguazas en Murcia hasta diez casos (FERNÁNDEZ, 1945).

Los punzones encontrados en la Cova del Cantal son bastante homogéneos en lo que se refiere a las secciones, siempre cuadradas, y al buen estado de conservación. El más largo tiene $12,2 \mathrm{~cm}$. mientras que el más corto sólo $3,6 \mathrm{~cm}$. variando los espesores de 0,25 a $0,30 \mathrm{~cm}$. Dos de ellos son de cobre arsenicado, uno de cobre puro y el último de bronce (según análisis realizados en el Departamento de Química Analítica de la Facultad de Ciencias de la Universidad de Alicante).

No extraña la presencia de cuatro punzones de metal en una cueva de enterramiento de estas características. Lo verdaderamente significativo es la composición de dos de ellos: el más pequeño de cobre puro (Fig. 23.5), el doblado de bronce (Fig. 23.2). El cobre arsenicado (composición de los dos restantes) (Fig. 23.1 y 23.2) es normal en este tipo de útiles y en contextos calcolíticos, según información oral de J. L. Simón quien piensa, por otro lado, que el bronce sería de un momento avanzado del II Milenio.

Cabe señalar la asociación espacial y cronológica en el Sector 5 de un punzón corto biapuntado (Fig. 23.5) junto a otro de igual forma y mayor longitud. Este hecho hablaría de la contemporaneidad de estos útiles a la vez que eliminaría la inclusión obligatoria del primero en el H. C. T.

Se observa una gran difusión de los punzones de sección cuadrada: en Villena (SOLER, 1981), Bañeres (APARICIO, et ALII, 1981), L'Alcoià (VICENS, 1984; TRELIS Y VICENS, 1984), Foia de Castalla, en el Fontanal con dos punzones biapun-

(2) Agradecemos al Dr. Pina la colaboración prestada en el análisis de la materia prima de los útiles de piedra pulida.

(3) Agradecemos a J. L. Simón y al Departamento de Química Analítica de la Facultad de Ciencias de la Universidad de Alicante la colaboración en el análisis de los útiles metálicos. 
tados de sección cuadrada (CERDÁ, 1983) y en otros muchos yacimientos tanto del País Valenciano como de Murcia. Sirvan como ejemplo la Coveta del Barranc del Castellet de Carricola (PLA, 1954), la Cavacha de la Ladera del Castillo de Chiva (FLETCHER, 1957), la Cova del Pic de Carcaixent (DE PEDRÓ, 1986) y los de la Sierra de la Tercia de Lorca (AYALA, 1987), en los que se ha llegado a encontrar cobre con un alto porcentaje de estaño (AYALA et ALII, 1987), y la Cueva de la Loma de los Peregrinos de Alguazas (FERNÁNDEZ, 1945).

El anillo (Fig. 23.6) no se pudo analizar por el riesgo de ser fracturado en el proceso de análisis, hecho agravado con su pertenencia a las colecciones privadas. Morfológicamente tiene muchos paralelos en la zona de Bañeres: Cova dels Anells, Cova del Partidor, y Cova de la Pedrera (APARICIO et ALII, 1981); en Villena: Cueva del Molinico, Cueva del Hacha, Cueva del Alto número 1 y Cueva de las Delicias (SOLER, 1981). También paralelos, pero realizados en plata, en la Cueva del Puntal de los Carniceros y Cuevas Oriental y Occidental del Peñón de la Zorra. Anillos con cronología campaniforme hay, entre otros, en la Cova dels Gats y Cova de la Xarta (BERNABEU, 1984). Este tipo de objetos está asociado en ocasiones a cuevas de enterramiento con elementos campaniformes, mientras que en otras forma parte de ajuares que carecen de ellos.

El puñal de lengüeta (Fig. 23.3), claramente enmarcable en el Campaniforme y utilizado tradicionalmente como fósil director de este momento, tiene muy poca representación en las zonas cercanas. Tan sólo conocemos un ejemplar en cueva de enterramiento en Villena, el de la Cueva Oriental del Peñón de la Zorra (al que habría que añadir el de Casa de Lara) (SOLER, 1981) y otro en el Rebolcat, en L'Alcoià (TRELIS y VICENS, 1984). Hay más ejemplos en el resto del País Valenciano, destacando los de Sima de la Pedrera de Polinya de la Ribera y Cova de la Xarta de Carcaixent, ambos con lengüeta dentada (como el de la Cova del Cantal) (BERNABEU, 1984).

Sólo hemos registrado un elemento de adorno en piedra en todo el conjunto de la cueva. Se trata de una cuenta de collar discoidal de piedra verde (Fig. 22.8), denominación propuesta por A. A. Huet (HUET, 1980). El autor expone en éste y en otro artículo (HUET y REIS, 1982) que los análisis realizados sobre adornos de esta materia prima demues- tran que en un 65-70\% de los casos es variscita férrica. También A. M. ${ }^{a}$ Muñoz (1971) ha llegado a las mismas conclusiones para adornos del País Vasco. La calaíta, nombre con el que se ha conocido tradicionalmente al material aludido, no es sino un nombre secundario de la turquesa que no puede ser aplicado para definir este tipo de piezas. Este mineral se ha hallado en algunas zonas de Almería, Zamora y Barcelona, localizándose una mina de extracción y transformación en época prehistórica en Gavá (Barcelona) (VILLALBA et ALII, 1986; 1989).

Conocemos la existencia de cuentas de collar de piedra verde en yacimientos cercanos geográficamente al que estamos analizando. Podemos citar, a modo de ejemplo, cinco yacimientos de Bañeres (APARICIO et ALII, 1981), cuatro de Villena (SOLER, 1981) y al menos dos de L'Alcoià (VICENS, 1984; VICENS y TRELIS, 1984).

Merecen ser destacadas las cuentas de collar discoidales hechas en piedra verde y procedentes de la Cova dels Gats en Alzira (BERNABEU, 1984) y las de la Coveta del Barranc del Castellet de Carricola (PLA, 1954) por ser de las pocas que hemos encontrado de igual forma que las de la Cova del Cantal en contextos relativamente cercanos.

En lo que a la cronología se refiere, debemos apuntar en primer lugar la aparición de las cuentas discoidales en el Neolítico Antiguo y Medio y su perduración hasta la Edad del Bronce (BERNABEU, 1979). Los yacimientos citados por su cercanía geográfica quedan encuadrados en el Calcolítico Pleno, contando con alguna adscripción al H. C. T. como ocurre en la Cova dels Gats (BERNABEU, 1984).

Los elementos de adorno en esta cueva son muy escasos: el anillo y la cuenta de collar son los únicos registrados en un yacimiento del que proporcionalmente al número de enterrados - e incluso en valores absolutos en algunos aspectos- se ha extraido una gran cantidad de objetos. Tampoco se registra entre su ajuar los objetos de hueso trabajado de carácter religioso, tan característicos de yacimientos cercanos como El Fontanal (SOLER DÍAZ, 1985) ni los de adorno. Descartados como razón para explicar este hecho factores como la no conservación por cuestiones físicas como la acidez de la tierra, cabría plantearse una variante en las costumbres cotidianas del grupo humano aquí enterrado, la fabricación de los adornos sobre materiales perecederos $o$, si se comprobase que la cueva es un lu- 
gar de enterramiento secundario, podría explicarse como un fallo en la recogida después de la descarnación de los cadáveres. Esto sólo sería válido para las cuentas de collar, ya que el resto de las ofrendas es de suponer que las depositarían en la cueva en el momento de llevar al fallecido, momento en el cual se consuma el enterramiento como tal. Con todo, hay otro yacimiento que sólo ha aportado una cuenta de collar de piedra verde, la Covacha Sepulcral del Camí Real en Albaida (BALLESTER, 1928), aunque este investigador piensa más en la dificultad de la recogida del material y en el hecho de que los enterramientos son secundarios.

Merced al trabajo realizado por D. Robey, hemos identificado entre los inhumados nueve individuos: cuatro hombres y tres mujeres. Uno de los varones tenía entre 14 y 16 años, otro de 18 a 21 y dos de 21 a 35 . Una de las mujeres era menor de 15 años y las otras dos tenían entre 15-18 y 21-35. Hay además dos niños, de siete $\mathrm{u}$ ocho meses uno y siete $\mathrm{u}$ ocho años otro, pero no se puede saber su sexo.

No se han podido ver conexiones anatómicas en los de huesos a pesar de haber realizado un análisis de dispersión a partir de los dibujos de excavación. Quizá algún enterramiento exhumado por los clandestinos respetase la posición anatómica. Parece pues que se trata de enterramientos secundarios depositados o incluso arrinconados en la cueva, al menos en el sector 5 .

En lo que a la fauna se refiere, además de los restos de roedores y la microfauna, abundantes por otro lado, hay que recalcar la existencia de dos maxilares inferiores de cabra u oveja junto a dos cráneos de las inhumaciones. Desconocemos su pertenencia o no al ajuar de los enterramientos pero cabe citar el yacimiento de Cova Santa de Vallada en el que también había restos de cráneos de estos animales, para Martí quizá relacionados con los inhumados (MARTI, 1981).

Los trabajos de excavación y el estudio de los materiales de los clandestinos han puesto de relevancia la utilización de la cueva en tres momentos distintos. La existencia en el Sector 5 de un conjunto de materiales y enterramientos en los que están presentes instrumentos de piedra pulida, puntas de flecha foliáceas, de pedúnculo y aletas y romboidales, punzones de metal biapuntados de sección cuadrada y vasijas con formas típicas de lo que se ha venido llamando Calcolítico Pleno (junto a otras que no lo son) define el primero de estos momentos. Esta cronología está apoyada por las ausencias en el re- gistro material de elementos como los microlitos geométricos por un lado y materiales relacionados con el H. C. T. por otro. Podemos asegurar, pues, la existencia de un sector que ha sido lugar de enterramiento en el Calcolítico Pleno o momentos avanzados de éste.

El hallazgo por los clandestinos de un puñal de lengüeta y un fragmento de cerámica con decoración campaniforme en el estrangulamiento que da acceso a la Sala 2, indica la utilización de la cueva en este momento. No podemos asegurar que los citados materiales correspondan a un enterramiento por carácter de las pruebas necesarias. A pesar de ello, conocemos varios ejemplos en los que se ha encontrado asociados a cuevas de enterramiento (BERNABEU, 1984).

La existencia de un punzón de sección cuadrada de bronce al que se le ha atribuido una fecha en torno al 1500 a. C. por su composición y la de una pequeña vasija carenada, demuestra la utilización de la cueva en la Edad del Bronce. Desconocemos la naturaleza de esta utilización, ya que los materiales pertenecen a colecciones privadas, siendo imposible por tanto relacionarlos con los enterramientos a pesar de conocer la costumbre de enterrar en grietas o cuevas naturales cercanas al poblado y saber de la existencia de uno correspondiente a este momento muy próximo a la cueva.

La cueva fue al menos visitada en época ibérica (como atestiguan varios fragmentos de cerámica pintada), en época romana - recordar el mortero de Terra Sigillata Clara D con decoración estampillada perteneciente a una forma Hayes 91 (450-500 d. C.)-y posiblemente en el período musulmán, hecho probado por el hallazgo de una aguja de bronce característica. La escasez de los hallazgos, unida a la imposibilidad de probar la existencia de niveles de ocupación claros por la alteración del relleno arqueológico de la sala en la que se encontraron y el que sean materiales de las colecciones privadas, induce a pensar que se trate de hallazgos aislados y ocasionales.

Para concluir podría decirse, siguiendo la terminología tradicional, que la cueva ha servido de lugar de enterramiento en un momento posiblemente avanzado del Eneolítico, y con probabilidad en el H. C. T. y en la Edad de Bronce. La investigación de estos períodos se ha visto revisada en los últimos años por los estudios de J. Bernabeu (1986) y de este autor con I. Guitart y P. Benito (1988), quienes proponen una nueva visión del III milenio a. C. ba- 
sada en que el Eneolítico es un período evolutivo dentro de la cultura de finales del Neolítico, que va transformándose con la llegada de las influencias del SE hasta el H. C. T. y la Edad del Bronce. Siendo el Eneolítico el último momento del Neolítico por la ausencia de cambios significativos que le den personalidad propia y siguiendo a los autores antes citados, la Cova del Cantal habría sido ocupada en el Neolítico IIB2, IIC y en la Edad del Bronce.

\section{BIBLIOGRAFÍA}

APARICIO PÉREZ et ALII, 1981: Las Raíces de Bañeres. Valencia.

AYALA JUAN, M. ${ }^{a}$ M., 1987: «Enterramientos calcolíticos de la Sierra de la Tercia. Lorca. Murcia. Estudio preliminar». Anales de Prehistoria y Arqueología, 3. Murcia.

AYALA JUAN, M. ${ }^{a}$ M. et ALII, 1987: «Análisis por fluorescencia de rayos $\mathrm{X}$ de los útiles de metal hallados en el enterramiento colectivo de La Salud. Lorca. Murcia. Enterramientos calcolíticos de la sierra de la Tercia. Lorca. Murcia. Estudio preliminar. Murcia.

BALLESTER TORMO, I., 1928: «La Covacha Sepulcral del Camí Real. Albaida». Archivo de Prehistoria Levantina, I. Valencia.

BERNABEU AUBÁN, J., 1979: «Los elementos de adorno en el Eneolítico Valenciano». Papeles del Laboratorio de Arqueología de Valencia. Saguntum, 14. Valencia.

- 1984: «El Vaso Campaniforme en el País Valenciano». Serie de Trabajos Varios del Servicio de Investigación Prehistórica, 80. Valencia.

- 1986: «El Eneolítico Valenciano ¿Horizonte cultural o cronológico?». El Eneolítico en el País Valenciano. Alcoy.

BERNABEU AUBÁN, J. et ALII, 1988: «El País Valenciano entre el final del Neolítico y la Edad del Bronce». Archivo de Prehistoria Levantina, 18. Valencia.

CERDÁ BORDERA, F. 1983: «Contribución al estudio de la Foia de Castalla (Alicante)». Lucentum II. Alicante.

FERNÁNDEZ AVILÉS, A., 1945: «La cueva funeraria eneolítica de la Loma de los Peregrinos (Alguazas, Murcia)». Archivo de Prehistoria Levantina II. Valencia.

FLETCHER VALLS, D. 1957: «La Covacha Sepulcral de la Ladera del Castillo (Chiva). Archivo de Prehistoria Levantina, 6. Valencia.

GONZÁLEZ PRATS, A., 1973: «Los enterramientos calcolíticos y del Bronce de Mas de Felip (Ibi, Alicante)». Revista del Instituto de Estudios Alicantinos, 9. Alicante.

- 1982: «El yacimiento epigravetiense del Fontanal de Onil (Alicante). Helike, 1. Elche.

GUITART I PERARNAU, I., 1989: «El Neolítico Final en el Alto Vinalopó (Alicante): Casa de Lara y La Macolla». Pa- peles del Laboratorio de Arqueología de Valencia. Saguntum, 22. Valencia.

HERNÁNDEZ PÉREZ, M. S., 1982: «Cueva de la Casa Colorá: un yacimiento eneolítico en el Valle Medio del Vinalopó (Alicante)». Lucentum, I. Alicante.

HUET B. GONÇALVES, A. A., 1980: «Elementos de adorno de cor verde provenientes de estaçoes arqueologicas portuguesas. Importância de seu etudo mineralogico». Trabalhos do Instituto de Antropología «Dr. Mendes Correa», 40. Porto.

HUET B. GONÇALVES, A. A. y LURDES REIS, M. ${ }^{a}$, 1982: «Etudo mineralogico de elementos de adorno de cor verde provenientes de estaçoes arqueologicas portuguesas». Trabalhos do Instituto de Antropologia «Dr. Mendes Correa», 43. Porto.

LÓPEZ GÓMEZ, A. y ROSELLÓ VERGER, V. M., 1978: Geografía de la provincia de Alicante. Alicante.

LLOBREGAT CONESA, E. A., 1966: «Estudios de los megalitos por los Leisner y las cuevas de enterramiento múltiple del País Valenciano». Archivo de Prehistoria Levantina, 11. Valencia.

MARTÍ OLIVER, B., 1981: «La Cova Santa (Vallada, Valencia)». Archivo de Prehistoria Levantina, 16. Valencia.

MARTÍN DE LA CRUZ, J. L., 1986: «Papa Uvas II». Excavaciones Arqueológicas en España. Madrid.

MUÑOZ AMIBILIA, A. M. ${ }^{a}$, 1971: «La calaita en el País Vascon. Munibe, 2-3. San Sebastián.

PASCUAL BENITO, J. L., 1986: «Les Jovades (Cocentaina). Notes per a l'estudi del poblament eneolitic a la conca del riu d'Alcoi. El Eneolítico en el País Valenciano». Alcoy.

PEDRÓ DE MITJÓ, M. ${ }^{a}$ J., 1986: «Les coves d'enterrament eneolitiques. La cova del Pic (Carcaixent, Valencia). El Eneolítico en el País Valenciano. Alcoy.

PLA BALLESTER, E., 1954: «La Coveta del Barranc del Castellet (Carricola, Valencia)». Archivo de Prehistoria Levantina, 5. Valencia.

SOLER GARCÍA, J. M. ${ }^{a}, 1981$ : El Eneolitico en Villena (Alicante). Valencia.

- 1986: «La Cueva del Molinico» (Villena, Alicante). El Eneolitico en el País Valenciano. Alcoy.

SOLER DÍAZ, J., 1985: «Los ídolos oculados sobre huesos largos del enterramiento de "EI Fontanal"' (Onil, Alicante)». Lucentum, 4. Alicante.

- 1988: «Bases para el establecimiento de un modelo de estudio en las industrias líticas de facies calcolítica de las cuevas de enterramiento múltiple valencianas». Ayudas a la Investigación del Instituto de Estudios Juan Gil-Albert. 1984 1985. Alicante.

TARRADELL, M., 1963: El País Valenciano: del Neolítico a la Iberización. Valencia.

TRELIS MARTI, J. y VICENS PETIT, J., 1985: «L'Eneolitic à les comarques de l'Alcoià-Comtat». Congrés d'Estudis de L'Alcoià-Comtat. Alcoy.

- 1986: «El Eneolítico en Alcoy. Bases para su estudio». El Eneolítico en el País Valenciano. Alcoy.

VICENS PETIT, J. M., 1984: «Eneolítico». Alcoy. Prehistoria y Arqueología. Cien años de investigación. Alcoy.

VILLALBA, M. ${ }^{a}$ J., et ALII, 1986: «Les mines neolitiques de Can Tintorer (Gavá)». Excavacions arqueologiques à Catalunya, 6. Barcelona.

- 1989: «Minería neolítica. Can Tintorer, una aportación fundamental». Revista de Arqueología, 96. Madrid. 